\title{
Enhanced curcumin loaded nanocellulose: a possible inhalable nanotherapeutic to treat COVID-19
}

\author{
Thennakoon M. Sampath U. Gunathilake • Yern Chee Ching $\mathbb{1} \cdot$ \\ Hiroshi Uyama · Nguyen Dai Hai · Cheng Hock Chuah
}

Received: 3 June 2021 / Accepted: 20 December 2021 / Published online: 4 January 2022

(C) The Author(s), under exclusive licence to Springer Nature B.V. 2022

\begin{abstract}
Nanocellulose/polyvinyl alcohol/curcumin (CNC/PVA/curcumin) nanoparticles with enhanced drug loading properties were developed by the dispersion of nanocellulose in curcumin/polyvinyl alcohol aqueous medium. Due to the physical and chemical nature of sulphuric acid hydrolyzed nanocellulose and the antiviral properties of curcumin, the possibility of using these nanoparticles as an inhalable nanotherapeutic for the treatment of coronavirus disease 2019 (COVID-19) is discussed. The adsorption of curcumin and PVA into nanocellulose, and the
\end{abstract}

T. M. S. U. Gunathilake · Y. C. Ching ( $\varangle)$

Centre of Advanced Materials (CAM), Faculty of

Engineering, University of Malaya,

50603 Kuala, Lumpur, Malaysia

e-mail: chingyc@um.edu.my

T. M. S. U. Gunathilake - Y. C. Ching

Department of Chemical Engineering, Faculty of

Engineering, University of Malaya,

50603 Kuala, Lumpur, Malaysia

H. Uyama

Department of Applied Chemistry, Graduate School of

Engineering, Osaka University, Osaka, Japan

N. D. Hai

Institute of Applied Materials Science, Vietnam Academy

Science and Technology, 01 TL29, District 12,

Ho Chi Minh City 700000, Vietnam

C. H. Chuah

Department of Chemistry, Faculty of Science, University

of Malaya, 50603 Kuala Lumpur, Malaysia presence of anionic sulphate groups, which is important for the interaction with viral glycoproteins were confirmed by Fourier transform infrared (FTIR) spectroscopy. FESEM images showed that the diameter of nanocellulose ranged from 50 to $100 \mathrm{~nm}$, which is closer to the diameter $(60-140 \mathrm{~nm})$ of severe acute respiratory syndrome coronavirus 2 (SARS-CoV-2). The solubility of poorly water-soluble curcumin was increased from $40.58 \pm 1.42$ to $313.61 \pm 1.05 \mathrm{mg} / \mathrm{L}$ with increasing the PVA concentration from 0.05 to $0.8 \%(\mathrm{w} / \mathrm{v})$ in aqueous medium. This is a significant increase in the solubility compared to curcumin's solubility in carboxymethyl cellulose medium in our previous study. The drug loading capacity increased by 22 -fold with the addition of $0.8 \%$ PVA to the nanocellulose dispersed curcumin solution. The highest drug release increased from $1.25 \pm 0.15 \mathrm{mg} / \mathrm{L}$ to $17.11 \pm 0.22 \mathrm{mg} / \mathrm{L}$ with increasing the PVA concentration from 0 to $0.8 \%$ in the drug-loaded medium. Future studies of this material will be based on the antiviral efficacy against SARS-CoV-2 and cell cytotoxicity studies. Due to the particulate nature, morphology and size of SARS-CoV-2, nanoparticle-based strategies offer a strong approach to tackling this virus. Hence, we believe that the enhanced loading of curcumin in nanocellulose will provide a promising nano-based solution for the treatment of COVID-19. 


\section{Graphical abstract}

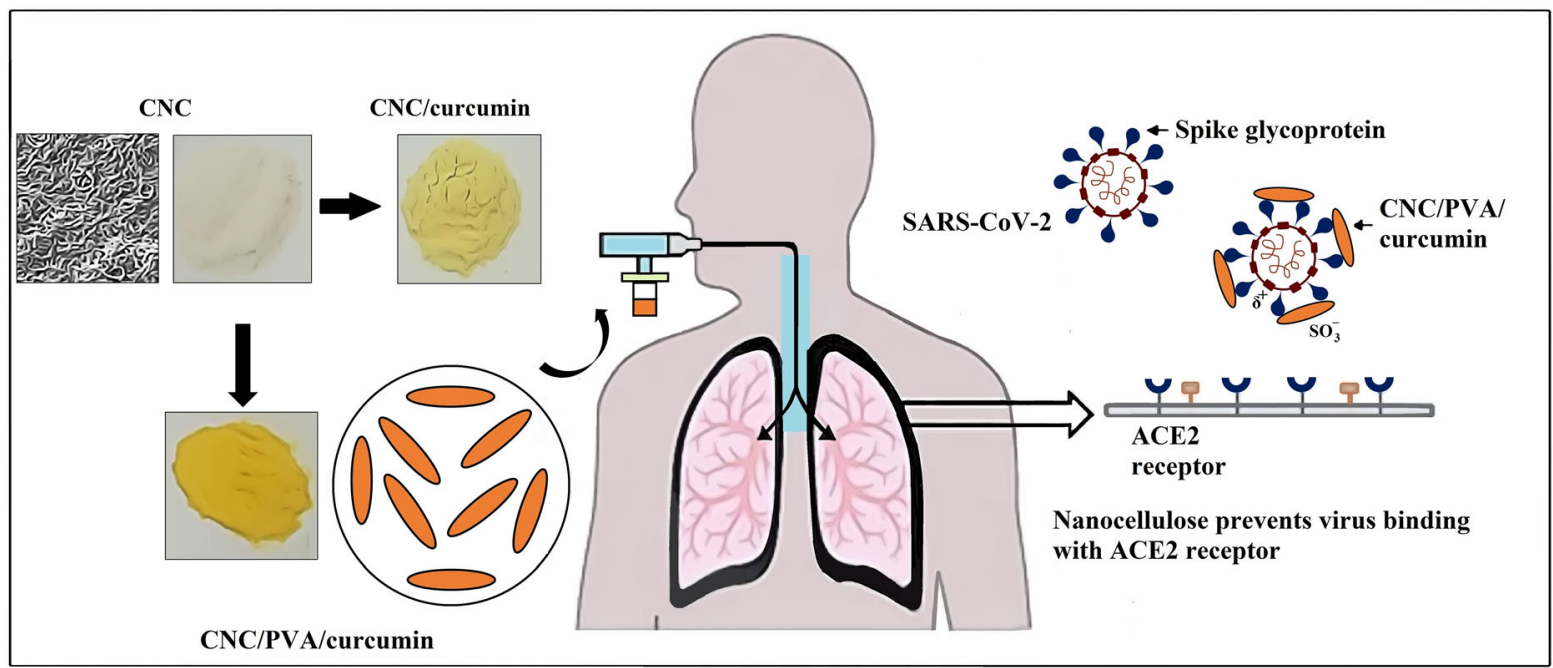

Keywords Nanocellulose - Curcumin - Polyvinyl alcohol $\cdot$ Inhalable nanotherapeutics $\cdot$ SARS-CoV-2

\section{Introduction}

High abundance, the relative ease with which its characteristics can be tuned through chemical modification, ease of formation into various polymeric architectures including hydrogels, nanoparticles, microspheres, beads, coatings etc. and reported biodegradability and biocompatibility properties have led to the use of celluloses in numerous applications of biomedical field (Ummartyotin et al. 2015; Yang et al. 2019). With this plenty of favorable chemical and physical properties, we believe that cellulose-based materials can be used as promising candidates in the development of medications for COVID-19 and/or enhancement of therapeutic efficacy of COVID-19 related medications. With the latest total number of reported cases $>171$ million individuals, the alarming and accelerated dissemination of severe acute respiratory syndrome coronavirus 2 (SARS-CoV-2) into a global pandemic has driven the need for quickly producible and reliable therapeutics (WHO 2021). Therefore, it is a great challenge for the researchers on the development of a vaccine/drug against the novel coronavirus.
Nanoparticles (NPs) have recently acquired immense importance as therapeutic delivery vehicles. These nanoformulations not only improve stability, but they also provide efficient delivery of drugs to targeted sites and long-term release. NPs can be surface-engineered with diverse kinds of treatments due to their unique physicochemical features, such as high surface-area-to-volume ratio, varying size and shape with distinct surface charge, making them a highly customized carrier for nanoformulations (Patra et al. 2018). Among different types of nanoparticles, biopolymer nanoparticles such as nanocelluloses are intriguing options for controlled therapeutic delivery applications owing to their stimuli-responsiveness, nontoxic, biocompatibility and biodegradability features. In previous studies, nanocelluloses have been used as carriers for various types of antivirals (Gunathilake et al. 2020a). For example, Zoppe et al. (2014) synthesized nanocelluloses by sulfuric acid hydrolysis to carry multivalent displays of tyrosine sulfate mimetic ligands and tested their efficiency in inhibiting alphavirus infection. Nanocrystal surfaces produced by sulfuric acid hydrolysis were decorated with anionic sulfate groups. Nanocellulose bearing multivalent displays of tyrosine sulfate mimetic groups showed increased inhibitory effect on alphaviral infection. In addition, Vedula et al. (2016) synthesized carboxymethyl cellulose acetate butyrate nanoparticles to deliver less aqueous soluble antiviral 
drug acyclovir (ACV). In vitro release results showed that the percentage of drug release from ACV loaded nanoparticles (nearly 55\%) was ten times higher than the release from the pure drug (nearly 5\%) over a period concerned. It was attributed to the increased surface area of nanoparticles enhancing the dissolution rates of $\mathrm{ACV}$ drug and increased release rates. In addition, it is reported that due to the negative surface charges, the sulfuric acid hydrolyzed nanocelluloses are well-dispersed in aqueous solutions and form a colloidal suspension. Recent studies report that the SARS-CoV-2 spike (S) glycoprotein is slightly more positively charged than SARS-CoV's $S$ proteins because it comprises four highly positive charged protein moieties and five less negative charged moieties. This might help it bind negatively charged areas of other molecules more efficiently through nonspecific and specific interactions (Hassanzadeh et al. 2020). In fact, that sulphuric acid hydrolyzed CNC surfaces having- $\mathrm{OSO}_{3}{ }^{-}$groups, it will provide the ability to electrostatically interact with the positively charged spike glycoproteins of SARS-CoV-2 (Roman and Winter 2004). This binding of nanocellulose with viral glycoproteins will prevent the interaction of the virus with angiotensin-converting enzyme 2 (ACE2) of cell receptors and inhibit the viral entry into the host cells. Recent studies have used this phenomenon to neutralize SARS-CoV-2. Schoof et al. (2020) developed nanobodies that disrupt the interaction between Spike and ACE2. Electron microscopy revealed that nanobody binds spike in a fully inactive conformation with its receptor binding domains locked into their inaccessible downstate, incapable of binding ACE2. In another study, Zhang et al. (2021) developed an inhalable formulation by mixing ACE2-containing nanocatchers with mucoadhesive excipient as the competitor with host cells for virus binding to protect cells from SARS-CoV-2 infection. Their results indicated that the mucoadhesive excipient introduced significantly prolong the retention of nanocatchers in the lung. In addition, the successful inhibition of pseudovirus infection using the ACE2-containing cellular nanovesicles was demonstrated in the ACE2-expressing mouse model.

Alternative therapies such as herbal/traditional medicines have been investigated to treat viruses for a long time and have gained interesting results in many studies. Among various types of herbal medications, many researchers have introduced curcumin as a potential antiviral drug to treat viruses. For example, Ting et al. (2018) studied the inhibitory effect of curcumin carbon dots on the process of viral RNA replication by using a coronavirus model (porcine epidemic diarrhoea virus (PEDV)). Curcumin carbon dot (CCM-CDs) therapy may alter virus's surface protein, preventing it from entering the cell. Furthermore, it may prevent synthesizing negative-strand RNA, viral budding, and reactive oxygen species accumulation by PEDV. Treatment with CCM-CDs also inhibits viral replication by increasing the production of interferon-stimulating genes (ISGs) and pro-inflammatory cytokines. Besides, curcumin has gained tremendous attention in the treatment of COVID-19 infection in recent researches. A molecular docking investigation by Khaerunnisa et al. (2020) showed that curcumin is one of the herbal medicines that may act as a potential inhibitor of COVID-19 main protease. In another study, Wen et al. (2007) showed the activity of curcumin against SARS-CoV 2 replication and inhibition of SARS-CoV main protease. The receptor-ligand complexes of the turmeric compounds and drugs used in experimental Covid-19 therapies were studied by Emirik (2020) in terms of docking scores and the binding free energy of proteinligand complexes. Their results indicated that the turmeric spice can inhibit the SARS-CoV-2 vital proteins and can be used as a therapeutic or protective agent against SARS-CoV-2 via inhibiting key proteins of the SARS-CoV-2 virus. According to computational modeling and simulations studies by Saadat et al. (2020) the interaction and stability of the docked keto and enol forms of curcumin with SARS-CoV-2 spike glycoprotein were verified by molecular dynamics simulations, free energy binding, and interaction energy. Similarly, Suravajhala, Parashar et al. (2020) found that curcumin possesses an antiviral protein binding affinity for SARS-CoV-2 proteins. Dandapat et al. (2020) also indicated that catechin and curcumin interact with corona (SARS-CoV2) viral spike protein and angiotensin converting enzyme 2 of the human cell membrane. Furthermore, by using system biology tools, Chen et al. (2020) reported that a combination of Vitamin C, curcumin, and glycyrrhizic acid may modulate the immunological and inflammatory responses linked with coronavirus infections. Moreover, Manoharan et al. (2020) and Zahedipour et al. (2020a) recently reviewed curcumin's possible benefits in treating COVID19 infection. 
Pulmonary or inhalation drug delivery provides a more convenient and efficient alternative for intravenous or oral administration of medications in order to reduce side effects. Recent studies suggest using silver nanoparticles to treat COVID-19 in its early stages by inhalation therapy. Zachar (2020) proposed a model technique and computation to achieve the antiviral minimal inhibitory concentration of silver particles in different regions of the respiratory tract as first-line therapy for halting infection development. The standard $5 \mu \mathrm{m}$ diameter droplet inhalation is suggested mainly for colloidal silver particles of $5 \mathrm{~nm}$ size. Similarly, Sarkar (2020) proposed nebulization of water dispersed $10 \mathrm{~nm}$ size silver nanoparticles with bronchodilators using a simple nebulizer machine or bi-level ventilation to yield better results for COVID-19 patients. AgNP's antiviral actions may be due to its binding to the surface glycoproteins of RNA viruses, which prevents the virus from fusing with host cells. Though several studies have suggested the inhalation delivery of silver nanoparticles as a potent treatment for COVID-19, these metal nanoparticles' adverse acute and chronic health effects are not well understood. Compared to metal nanoparticles, bionanoparticles are considered safe in biomedical applications due to their inherent biodegradability and biocompatibility properties. Nanocellulose manufacture has been found to be safe (Environment Canada has listed nanocelluloses as a "nontoxic" domestic material), inhaled spray-dried nanocellulose powders have demonstrated no deleterious effects on the lungs, and ecotoxicological characterization has demonstrated nanocelluloses to have minimal toxicity potential and environmental risk (Kovacs et al. 2010). Furthermore, the studies of the interaction of nanocellulose with a multi-cellular in vitro model of the epithelial airway barrier following realistic aerosol exposure by Endes et al. (2015) showed that shorter nanocelluloses $(237 \pm 118 \times 29 \pm 13 \mathrm{~nm})$ are readily engulfed and cleared from the cell surface. In another study, Vartak et al. (2021) formulated an aerosolized nanoliposomal carrier for remdesivir against SARS-CoV-2. In this study, the authors developed specialized, nanosized particles containing the drug remdesivir that can be administered directly into the lungs. This could drastically minimize side effects, enhance efficacy and allow easy self-administration at the site of infection. Results demonstrated minimal cytotoxicity in A549 cells and retained monolayer integrity of Calu-3 cells. Remdesivir showed sustained release, with complete drug release obtained within $50 \mathrm{~h}$ in simulated lung fluid.

Systemic drug delivery by inhalation (oral and nasal) is a promising alternative to oral or parenteral administration of drugs. High bioavailability, rapid onset of action due to wide surface area for absorption, self-administration, increased patient compliance, non-invasive nature, minimal drug degradation, and high solute permeability are all benefits of inhaled drug delivery. Antibiotics, proteins, peptides, chemotherapeutics, interferon, antitrypsin, protease inhibitors, deoxyribonucleases, vaccines, and many other drugs have been delivered locally via the pulmonary route (Mahmud and Discher 2011; Sung et al. 2007). Liposomes, solid lipid nanoparticles, lipid or polymeric micelles, polymeric nanoparticles, and dendrimers are some of the nanocarriers that have been studied as potential drug delivery systems. In this study, we suggest the use of nanocellulose for inhalable delivery of the antiviral drug curcumin. Though several studies have employed biopolymer nanoparticles such as gelatin, chitosan, alginate, and synthetic polymers, including poloxamer, poly(lacticco-glycolic) acid, and poly(ethylene glycol) as nanocarriers, a limited number of studies have reported on the use of nanocellulose as a carrier for nasal drug delivery (Menon et al. 2014; Muralidharan et al. 2015; Thennakoon et al. 2021). The use of sulphuric acid hydrolysis to prepare nanocellulose will provide many advantages such as ease of the preparation of tunable particle size, morphology and surface characteristics, including the incorporation of anionic surface charge. Integration of those features to nanocellulose will help to improve drug loading capacity, and stronger barriers cross permeability, enhanced cellular uptake, longer lung retention, and a better possibility of penetrating mucus in the airway. Due to these facts, we believe this study will provide a better initiative to consider nanocellulose as a novel nanocarrier for future inhalable drug delivery systems.

Since curcumin is poorly water-soluble, in this study, we use water-soluble biodegradable biopolymer, PVA, to improve the solubility of curcumin. Though Tween 20 and carboxymethyl cellulose have succeeded in improving the curcumin solubility from our previous studies, this study requires a surfactant that improves the curcumin solubility in the acidic medium and hence in this study, $\mathrm{pH}$-independent 
water-soluble PVA has been used. Due to hydroxyl and acetyl groups, we believe that PVA will form micelles-like structures in the aqueous medium and facilitate enhancing the solubility of curcumin. The enhancement of curcumin's solubility will significantly affect the improvement of the drug loading in nanocellulose. Enhanced loading of curcumin in nanocellulose will provide a promising nano-based approach for the treatment of COVID-19.

\section{Materials and methods}

\section{Materials}

Microcrystalline cellulose with a particle size of $20 \mu \mathrm{m}$ (CAS:9004-34-6) was purchased from SigmaAldrich. Hydrochloric acid, methanol and sulfuric acid were purchased from Friendemann Schmidt Chemicals. Polyvinyl alcohol (Kuraray Poval 220S, molecular weight $78 \mathrm{kDa}$, viscosity $27-33 \mathrm{mPa} \bullet \mathrm{s}$, degree of hydrolysis of $87 \%-89 \%$ ) was purchased from Kuraray Co., Ltd., Kurashiki, Japan.

\section{Methodology}

\section{Extraction of curcumin}

Curcumin was extracted from dried rhizomes of turmeric using a solvent extraction method. $500 \mathrm{~g}$ of dried rhizomes were crushed and immersed in methanol for 3 days. Then, the extract was filtered using the Whatman filter paper (pore size $0.2 \mu \mathrm{m}$ ). After that, the filtrate was evaporated under a vacuum to produce a semi-solid oily mass.

\section{Preparation of CNCs}

The sulfuric acid hydrolysis technique was used to synthesize cellulose nanocrystals (CNCs). $10 \mathrm{~g}$ microcrystalline cellulose (MCC) was first mixed with distilled water in a flask. The flask was placed in an ice bath, and sulfuric acid was added dropwise (to avoid a temperature spike) while constantly stirring until the required acid concentration of $64 \%(\mathrm{w} / \mathrm{w})$ was obtained. After that, the suspension was rapidly stirred for $60 \mathrm{~min}$ at $45^{\circ} \mathrm{C}$. Following acid hydrolysis, the suspension was nixed with cooled deionized water $1: 10(\mathrm{v} / \mathrm{v})$ to stop the reaction and washed with deionized water using centrifuge cycles (at $6000 \mathrm{rpm}$ for $10 \mathrm{~min}$ ). The clear solution was removed from the precipitate, and distilled water was added to the recipient and mixed to remove excess acid from the suspension. This process was carried out five times. The slurry was then placed on dialysis membranes, dialyzed for $24 \mathrm{~h}$, and then dipped in distilled water for another $24 \mathrm{~h}$ until it reached a neutral $\mathrm{pH}$. Finally, the CNC suspension was subjected to a $10 \mathrm{~min}$ ultrasound treatment to prevent the formation of aggregates (Sampath et al. 2017; Shi et al. 2021; Udeni Gunathilake et al 2016).

\section{Solubility studies}

The solubility of curcumin was determined in a slightly acidic medium ( $\mathrm{pH} 6$ ). This is to maintain the experimental condition similar to the $\mathrm{pH}$ of mucosal airway and to ensure the stability of curcumin. The $\mathrm{pH}$ of the medium was adjusted to $\mathrm{pH} 6$ by adding hydrochloric acid dropwise to distilled water. After that, an excess amount of curcumin $(100 \mathrm{mg})$ was added to the prepared acidic $(\mathrm{pH} \mathrm{6)}$ aqueous medium $(100 \mathrm{~mL})$ and mixed with PVA. To study the effect of PVA concentration on the solubility of curcumin, a series of curcumin solutions were prepared using different concentration of PVA [0.05\%, $0.1 \%, 0.2 \%, 0.4 \%$ and $0.8 \%(\mathrm{w} / \mathrm{v})]$. Then sample containers were wrapped in aluminum foil to prevent photo-degradation. After that, the mixture was stirred using a magnetic stirrer (at a speed of $350 \mathrm{rpm}$ ) for $12 \mathrm{~h}$. Finally, the solutions were centrifuged $(10,000 \mathrm{rpm}$ for $10 \mathrm{~min})$ and dissolved curcumin was determined using UV-Vis spectroscopic method. The tests were performed in triplicates, and average values were reported.

\section{Drug loading}

Excess amount of curcumin (100 mg) was added to acidic (pH 6) aqueous medium (100 mL) with PVA at different concentration $[0.05 \%, 0.1 \%, 0.2 \%, 0.4 \%$ and $0.8 \%(\mathrm{w} / \mathrm{v})]$ and stirred for $12 \mathrm{~h}$. After that, the solutions were centrifuged (10,000 rpm for $10 \mathrm{~min})$ and supernatant was separated. A constant amount of CNC (0.42 g) was then dispersed in $100 \mathrm{~mL}$ supernatants and stirred (at a speed of $350 \mathrm{rpm}$ ) for $24 \mathrm{~h}$. After that, the CNC suspensions (in PVA medium) were centrifuged (6000 rpm for $20 \mathrm{~min}$ ), and the 
remaining amount of curcumin in the supernatant was determined using UV-Vis spectroscopic method. The drug loading capacity of CNC was calculated using Eq. (1). The tests were performed triplicates and average values were reported.

Drugloadingcapacity

$$
=\frac{\text { Absorbed amount of drug from the solution }}{\text { Weight of nanocellulose }} \times 100 \%
$$

\section{In vitro drug release}

Excess amount of curcumin $(100 \mathrm{mg})$ was added to acidic (pH 6) aqueous medium (100 mL) with PVA at different concentration $[0.05 \%, 0.1 \%, 0.2 \%, 0.4 \%$ and $0.8 \%(\mathrm{w} / \mathrm{v})]$ and stirred for $12 \mathrm{~h}$. After that, the solutions were centrifuged (10,000 rpm for $10 \mathrm{~min})$ and supernatant was separated. A constant amount of CNC (0.42 g) was then dispersed in $100 \mathrm{~mL}$ supernatants and stirred (at a speed of $350 \mathrm{rpm}$ ) for $24 \mathrm{~h}$. After that, the CNC suspensions (in PVA medium) were centrifuged (6000 rpm for $20 \mathrm{~min}$ ), and curcumin loaded CNC was air dried. The composition of nanocellulose used for in vitro drug release studies is mentioned in Table 1.

In vitro drug release from curcumin loaded $\mathrm{CNCs}$ were studied in an acidic medium (pH 6). Drug loaded CNC was dispersed in an acidic medium, and the concentration of released curcumin was determined using the UV-Vis spectroscopic method. The drug release was determined by withdrawing $3 \mathrm{~mL}$ of the medium at prefixed time intervals and returned it back to the solution after the analysis. The tests were replicated three times, and average values were obtained.

\section{Drug activity}

The UV-visible spectra of pure curcumin and the curcumin released from nanocellulose were obtained by scanning the drug solutions using UV-visible spectrophotometer (scan range 300-700 nm). Drug activity was determined by comparing the spectra [the absorption maxima $(\lambda \max )]$ of pure and released drugs.

\section{FTIR study}

The FTIR spectra of extracted curcumin, PVA, nanocellulose, curcumin loaded nanocellulose, and curcumin/PVA loaded nanocellulose were obtained using the $\mathrm{KBr}$ pellet method and PerkinElmer FTIR spectrometer over the range $4000-500 \mathrm{~cm}^{-1}$.

\section{Morphology}

The morphology of the microcrystalline cellulose and nanocellulose were studied using a field emission scanning electron microscope (FESEM, Auriga, Zeiss). Few drops of samples dispersed in distilled water were put on the surface of aluminum foil and airdried before the analysis. The FESEM observation was done at $1 \mathrm{kV}$ accelerating voltage.

Table 1 The composition of nanocellulose used for in vitro drug release studies

\begin{tabular}{|c|c|c|c|c|}
\hline \multirow[t]{2}{*}{ Nanoformulations } & \multicolumn{3}{|c|}{ The composition of the drug loading medium } & \multirow[t]{2}{*}{ The amount of loaded curcumin (per $1 \mathrm{~g}$ of $\mathrm{CNC}$ ) } \\
\hline & $\mathrm{CNC}(\mathrm{w} / \mathrm{v}) \%$ & Curcumin (w/v) \% & PVA (w/v) \% & \\
\hline $\mathrm{CNC} / \mathrm{PVA} 0 /$ curcumin & 0.42 & 0.1 & 0 & $0.40 \pm 0.01$ \\
\hline $\begin{array}{l}\text { CNC/PVA0.05/ } \\
\text { curcumin }\end{array}$ & 0.42 & 0.1 & 0.05 & $1.46 \pm 0.20$ \\
\hline $\mathrm{CNC} / \mathrm{PVA} 0.1 /$ curcumin & 0.42 & 0.1 & 0.1 & $3.87 \pm 0.15$ \\
\hline $\mathrm{CNC} / \mathrm{PVA} 0.2 /$ curcumin & 0.42 & 0.1 & 0.2 & $7.68 \pm 0.20$ \\
\hline $\mathrm{CNC} / \mathrm{PVA} 0.4 /$ curcumin & 0.42 & 0.1 & 0.4 & $8.36 \pm 0.78$ \\
\hline $\mathrm{CNC} / \mathrm{PVA} 0.8 /$ curcumin & 0.42 & 0.1 & 0.8 & $8.90 \pm 0.20$ \\
\hline
\end{tabular}




\section{Results and discussion}

FTIR study

Figure 1 illustrates the FTIR spectra of extracted curcumin, $\mathrm{CNC}$ and curcumin incorporated $\mathrm{CNC}$. The classic approach of running the IR spectrum is by preparing a $\mathrm{KBr}$ disc. Attenuated total reflection (ATR) is a technique that enables direct sample measurement for FTIR. Some research indicated that both these methods give the same result. However, we found from this study that the $\mathrm{KBr}$ disc technique has a higher resolution than the ATR. The FTIR spectrum of CNC demonstrated pure cellulose's characteristic peaks. The broad peak around $3434 \mathrm{~cm}^{-1}$ is due to the $\mathrm{O}-\mathrm{H}$ stretching vibration of the hydrogen-bonded cellulosic hydroxyl groups. Here the hydrogen-bonded $\mathrm{O}-\mathrm{H}$ stretch peak is much broader because the hydrogen bonds vary in strength (Larsen et al. 2007). The peak that appeared at $1207 \mathrm{~cm}^{-1}$ is due to the $\mathrm{C}-\mathrm{H}$ stretching vibration of cellulose (Sajjad et al. 2020). The peaks that appeared at $2136 \mathrm{~cm}^{-1}$ and $1647 \mathrm{~cm}^{-1}$ are due to moisture absorption. $1647 \mathrm{~cm}^{-1}$ peak is attributed to the $\mathrm{H}-\mathrm{O}-\mathrm{H}$ angle vibration, and the peak at $2136 \mathrm{~cm}^{-1}$ is due to scission and rocking vibrations of water (Olsson and Salmén 2004). The peaks in the range of $1431-1453 \mathrm{~cm}^{-1}$ is due to the symmetric bending of $\mathrm{CH}_{2}$ and the absorption peaks at 1376-1321 $\mathrm{cm}^{-1}$ related to the $\mathrm{C}-\mathrm{H}$ and $\mathrm{C}-\mathrm{O}$ bending vibration of the polysaccharides (Aguayo et al. 2018). The band that appeared around $1161 \mathrm{~cm}^{-1}$ range was due to asymmetric stretching vibrations of $\mathrm{C}-\mathrm{O}-\mathrm{C}$ in the 1,4-glycosidic linkages of d-glucose units (Zheng et al. 2019). In addition, the removal of amorphous components during acid hydrolysis can result in substituting hydroxyl groups $(-\mathrm{OH})$ by sulphate groups $\left(\mathrm{O}-\mathrm{SO}_{3}{ }^{-}\right)$on the nanocellulose surface. The presence of surface sulphate groups can be confirmed by the $1165 \mathrm{~cm}^{-1}$ and $1431 \mathrm{~cm}^{-1}$ peaks, which corresponding to the symmetric $\mathrm{S}=\mathrm{O}$ (in the range of $1200-1150 \mathrm{~cm}^{-1}$ ) and asymmetric $\mathrm{S}=\mathrm{O}$ (in the range of $1430-1330 \mathrm{~cm}^{-1}$ ) stretching vibrations, respectively. However, the sulphate stretching vibration peaks may overlap with glycosidic link vibrations. Furthermore, the weaker peak at $814 \mathrm{~cm}^{-1}$ may also be due to the $\mathrm{C}-\mathrm{O}-\mathrm{S}$ stretching vibration of the sulphate group on the surface of nanocellulose (Septevani et al. 2017). As an antiviral nanotherapeutic, the interaction of nanoparticle with viral particles is an important factor, considering the antiviral drug's therapeutic efficacy. In this case, negatively charged ionized surface sulphate groups attached to
Fig. 1 FTIR spectra of nanocellulose, curcumin and curcumin loaded nanocellulose

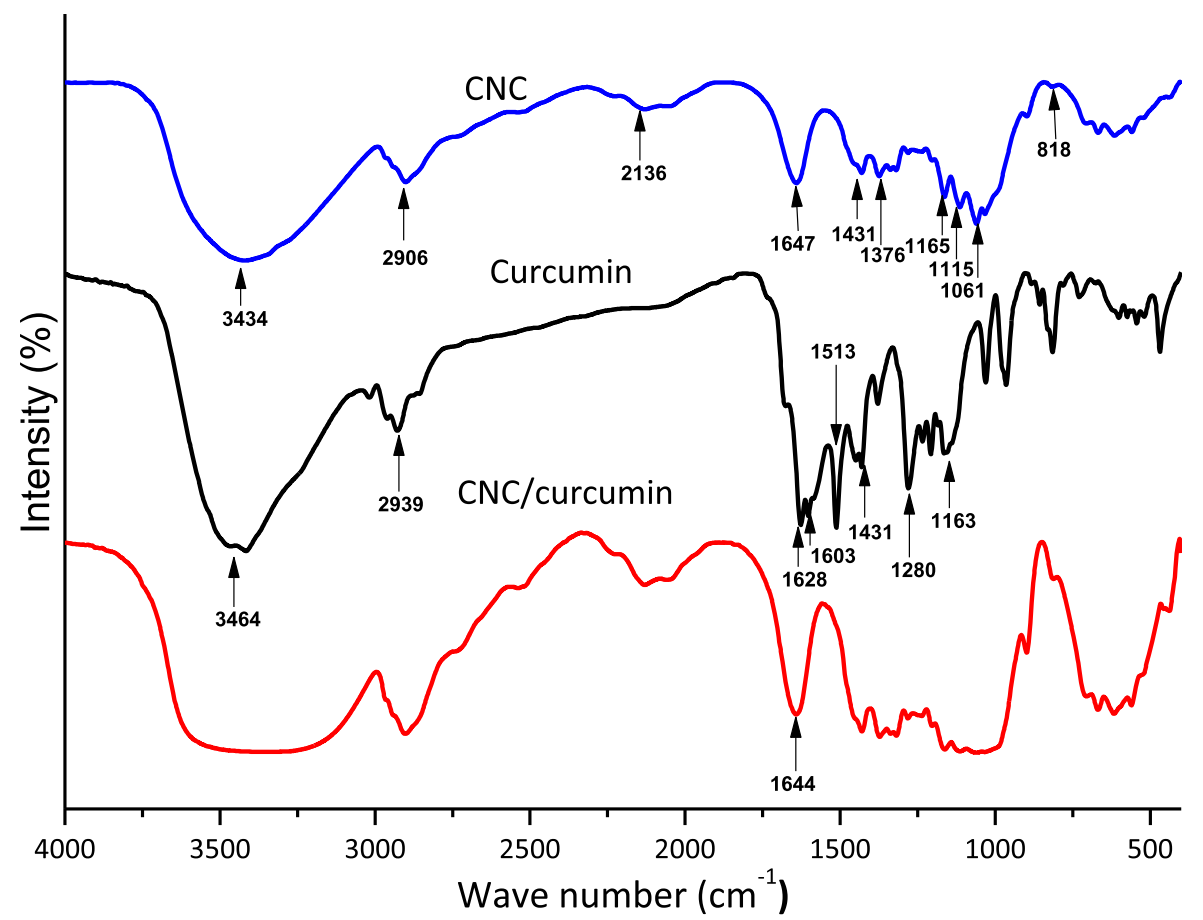


nanocellulose will provide the ability to binding with the positively charged lipid bilayer of viruses.

The extracted curcumin FTIR spectrum is similar to the FTIR spectrum of curcumin obtained from turmeric powder in earlier research (Bich et al. 2009; Fugita et al. 2012). Furthermore, we compared and confirmed the occurrence of characteristic peaks of extracted curcumin from turmeric and commercial curcumin obtained from Himedia Co. in our prior work (Gunathilake et al. 2018). In the curcumin spectrum, the broad peak at $3464 \mathrm{~cm}^{-1}$ is attributed to the stretching vibration of phenolic $\mathrm{O}-\mathrm{H}$. This $\mathrm{OH}$ stretch peak is less broad compared to nanocellulose's $\mathrm{OH}$ stretch peak. This may be attributed to the fewer hydrogen bonding interactions in curcumin compared to nanocellulose. The peak at $2939 \mathrm{~cm}^{-1}$ is responsible for the aromatic $\mathrm{C}-\mathrm{H}$ stretch vibrations. The peaks at $1628 \mathrm{~cm}^{-1}$ and $1603 \mathrm{~cm}^{-1}$ are due to $\mathrm{C}=\mathrm{O}$ stretching and aromatic ring stretching, respectively. The peak corresponding to olefinic bending vibration of $\mathrm{C}-\mathrm{H}$ bound to benzene ring appeared at $1513 \mathrm{~cm}^{-1}$, while $\mathrm{C}-\mathrm{C}$ vibrations occurred at $1431 \mathrm{~cm}^{-1}$. The peaks that appeared at $1280 \mathrm{~cm}^{-1}$ and $1163 \mathrm{~cm}^{-1}$ are due to the $\mathrm{C}=\mathrm{O}$ stretching vibrations attached to the aromatic ring and $\mathrm{C}-\mathrm{O}-\mathrm{C}$ stretching vibrations, respectively (Ching et al. 2019). Curcumin contains three reactive functional groups linked with its various biological functions, as determined by its FTIR spectrum: one diketone moiety and two phenolic groups. Important chemical reactions related to its biological activity include $\mathrm{C}=\mathrm{O}$ groups as hydrogen acceptors and C-4 as a hydrogen donor. These functional groups will also contribute to the antiviral properties of curcumin. Curcumin has been shown to inhibit SARS-CoV-2 replication by interacting with the spike glycoprotein and inhibiting ACE2, the viral non-structural protein Nsp15, or the main viral protease, according to recent research (Zahedipour et al. 2020b).

In $\mathrm{CNC} /$ curcumin spectrum, the characteristic peaks related to $\mathrm{CNC}$ functional groups are more prominent. The main feature observed in the $\mathrm{CNC}$ / curcumin spectrum is the increase of moisture absorption. It is evident by the broadening and shifting of the $\mathrm{OH}$ stretch band to a lower wavelength region and the increase of the intensity of the water peak $1644 \mathrm{~cm}^{-1}$. This may be due to the introduction of hydrophobic curcumin molecules within hydrophilic cellulose chains causing exposure of more hydroxyl groups of
CNC chains, which result in absorption of more water molecules. These hydrogen-bonded (with $\mathrm{H}_{2} \mathrm{O}$ ) $\mathrm{OH}$ groups vary in strength and require less energy for stretching vibrations. Therefore, the $\mathrm{OH}$ stretching band is broader and shifting to a lower wavelength region. In addition, the shifting of water peak from 1647 to $1644 \mathrm{~cm}^{-1}$ was observed. This may be due to the interaction of curcumin with CNC chains. Similar findings were also reported by previous researches. In addition, the peak broadenings in the regions of $987 \mathrm{~cm}^{-1}-1165 \mathrm{~cm}^{-1}$ and $813 \mathrm{~cm}^{-1}-461 \mathrm{~cm}^{-1}$ were also observed due to the curcumin and $\mathrm{CNC}$ interactions. However, there were no new peaks appeared in the $\mathrm{CNC} /$ curcumin spectrum.

Figure 2 displays the FTIR spectra of PVA, curcumin loaded nanocellulose, and curcumin/PVA adsorbed nanocellulose. The FTIR spectrum of PVA indicated a broad absorption peak at $3444 \mathrm{~cm}^{-1}$, corresponding to $\mathrm{OH}$ stretching vibration. The peaks at $2947 \mathrm{~cm}^{-1}$ and $2912 \mathrm{~cm}^{-1}$ are due to the $\mathrm{C}-\mathrm{H}$ symmetric and asymmetric stretching vibrations. The peak at $1735 \mathrm{~cm}^{-1}$ is due to the $\mathrm{C}=\mathrm{O}$ and $\mathrm{C}-\mathrm{O}$ stretching of the remaining acetate groups of PVA. The water peak is appeared at around $1649 \mathrm{~cm}^{-1}$. The band at $1440 \mathrm{~cm}^{-1}$ is due to the bending of $\mathrm{CH}_{2}$ groups. The peaks at $1379 \mathrm{~cm}^{-1}$ and $1337 \mathrm{~cm}^{-1}$ are due to the bending vibrations of $\mathrm{CH}_{3}$ groups. The peaks at $1264 \mathrm{~cm}^{-1}, 1099 \mathrm{~cm}^{-1}, 849 \mathrm{~cm}^{-1}$ and $607 \mathrm{~cm}^{-1}$ are due to the $\mathrm{C}-\mathrm{O}$ stretching of alcohol groups. In the CNC/PVA/curcumin spectrum, a shoulder-type peak appeared just to the left of the water peak. This is corresponding to the stretching of $\mathrm{C}=\mathrm{O}$ and $\mathrm{C}-\mathrm{O}$ from the remaining acetate groups of PVA. There was no significant difference between $\mathrm{CNC} /$ curcumin spectrum and $\mathrm{CNC} / \mathrm{PVA} /$ curcumin spectrum. However, the decrease in the water peak intensity and the less broadening of the $\mathrm{OH}$ stretch peak show CNC/PVA/curcumin absorbs less moisture than $\mathrm{CNC}$ /curcumin. This may be due to the hydrogen bonding interactions of PVA with CNC hydroxyls lowers the binding of water molecules to $\mathrm{CNC}$ chains via hydrogen bonding. Moreover, no new peaks appeared in the CNC/PVA/curcumin spectrum, indicating no chemical reactions between PVA, curcumin and $\mathrm{CNC}$. 
Fig. 2 FTIR spectra of PVA, curcumin loaded nanocellulose and curcumin/PVA adsorbed nanocellulose

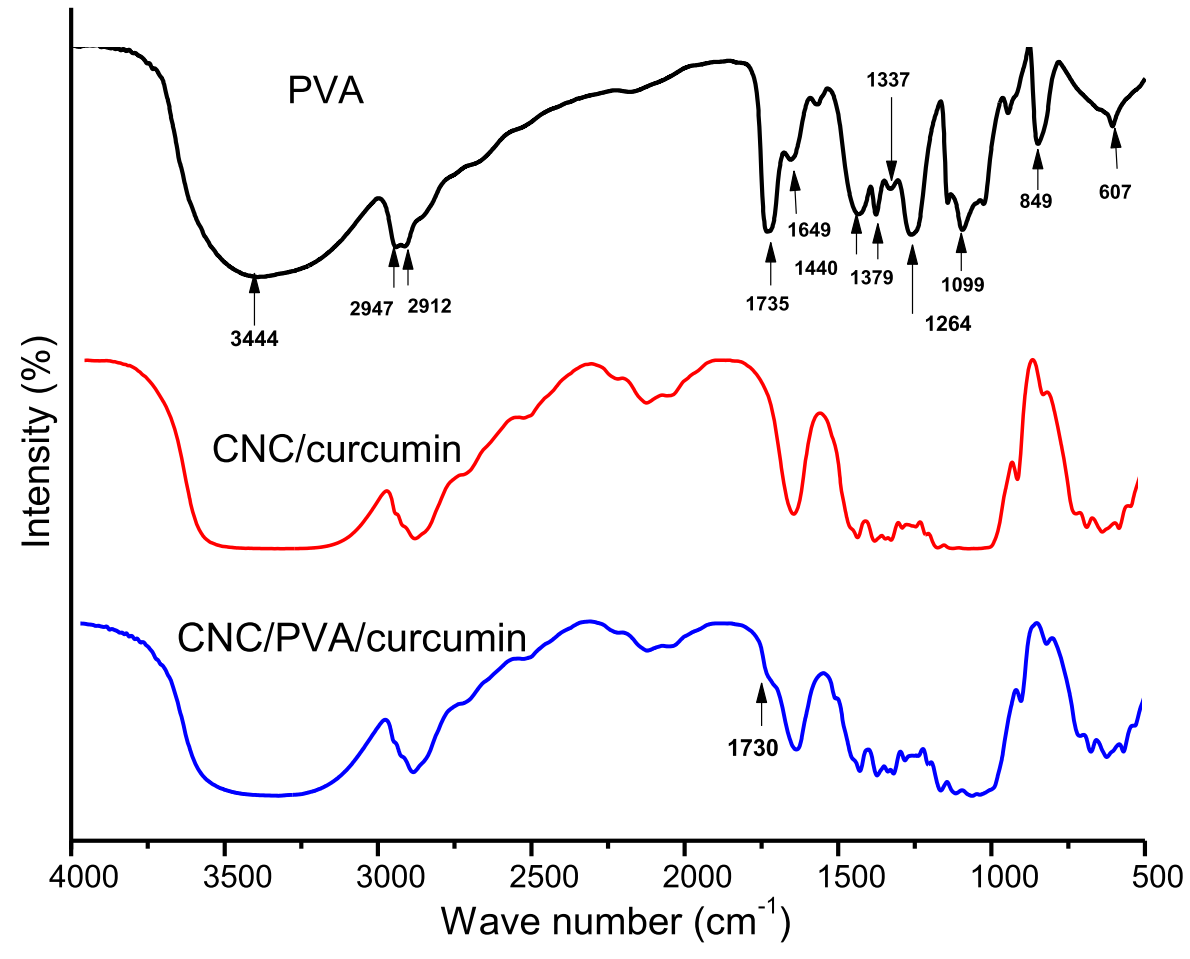

Morphology

The isolation of nanocellulose from microcrystalline cellulose was successfully executed using the sulphuric acid hydrolysis method. The nanocellulose $1 \%$ suspension was prepared in distilled water, and undispersed $\mathrm{CNC}$ aggregates were removed using a mild sonication method. After that, the suspension was dispersed in aluminum foil and air-dried. The morphology of nanocellulose was studied using FESEM under accelerating voltage of $1 \mathrm{kV}$ to confirm the successful extraction of CNC. Here, the diameter and size of cellulose structures were reduced from micron to nanometer size due to the removal of amorphous microcrystalline cellulose regions, leaving nanoscale rod-like structures (Fig. 3). The diameter of the CNC ranged from 50 to $100 \mathrm{~nm}$ (Image J software). CNCs presented more densely packed fibrous cellulose networks due to the intermolecular hydrogen bonding and strong hydrophilic interaction between the cellulosic chains. The diameter of CNCs was similar to the values reported for CNCs obtained from sulfuric acid hydrolysis by Wulandari et al. (2016) and Nascimento et al. (2016). Wulandari et al. (2016) used 50\% sulfuric acid at $40{ }^{\circ} \mathrm{C}$, and Nascimento et al. (2016) used $63.7 \%$ sulfuric acid at $45{ }^{\circ} \mathrm{C}$.

SARS-CoV-2, a positive-sense single-stranded RNA virus, is covered by an envelope with glycoprotein spikes. SARS-CoV-2 spike glycoprotein binds to the angiotensin-converting enzyme 2 (ACE2) receptors on the surface of host cells. The most popular treatment approaches focus on disrupting this critical event since binding the $\mathrm{S}$ protein to ACE2 is essential for the first infection stage.

SARS-CoV-2 particles are 60 to $140 \mathrm{~nm}$ in diameter (Bar-On et al. 2020). Due to the particulate nature, morphology and size of SARS-CoV-2, nanoparticle (NP)-based strategies offer a strong approach to tackling this virus. The presence of surface $-\mathrm{OSO}_{3}{ }^{-}$groups with negative charges and nanoscale rod-like structures of nanocellulose provide the ability to binding with the positively charged domains of spike glycoproteins of the virus. It will prevent the virus from binding with ACE2 receptors and internalizing the virus into the host cell, interfering with viral replication. The proposed inhibition mode of $\mathrm{CNC} /$ PVA/curcumin against SARS-CoV-2 infection is illustrated in Fig. 4. Similarly, these types of electro statistic interactions of nanomaterials have been used 

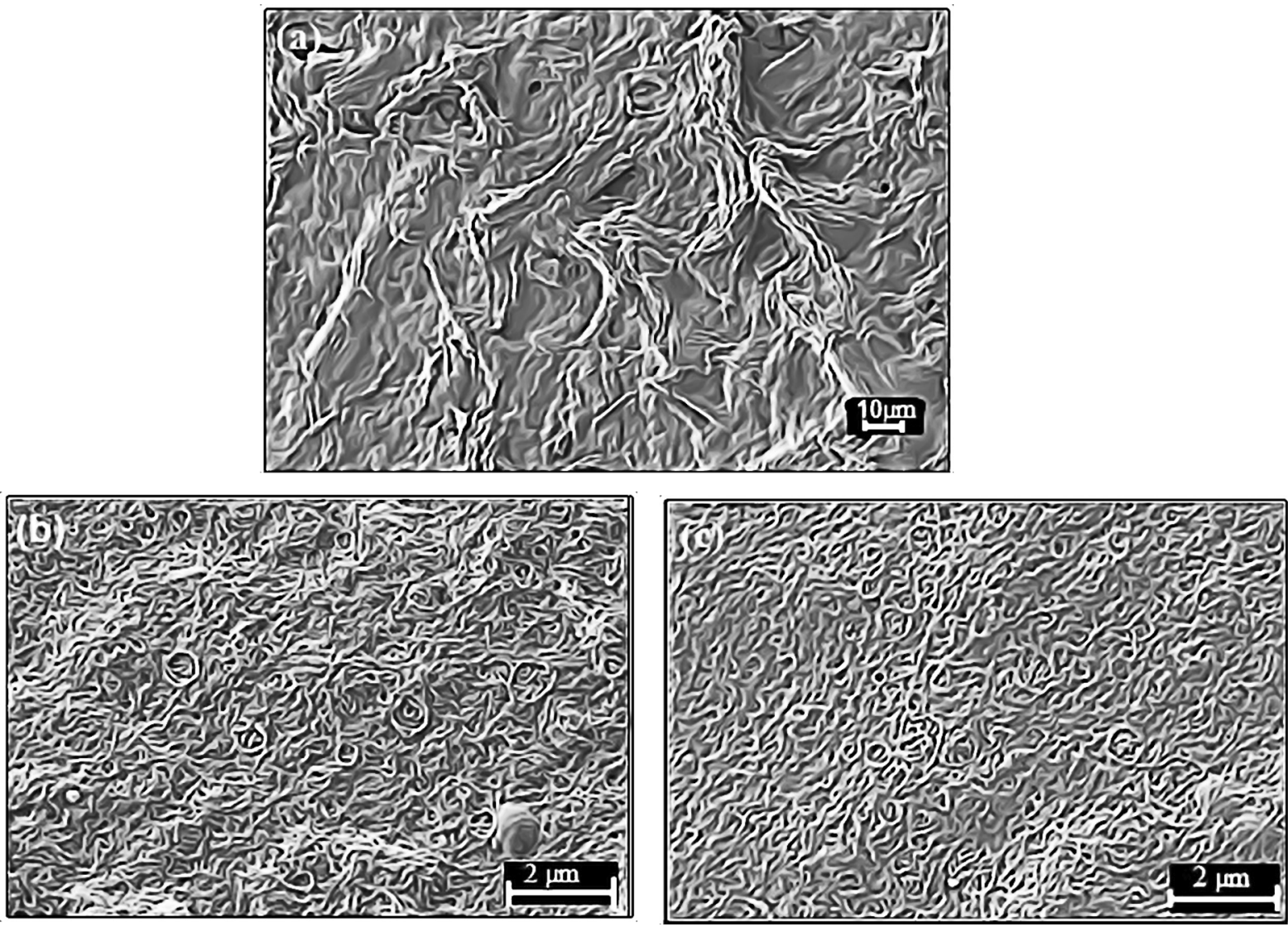

Fig. 3 FESEM images of a microcrystalline cellulose; $\mathbf{b}$ and $\mathbf{c}$ sulphuric acid hydrolyzed nanocellulose

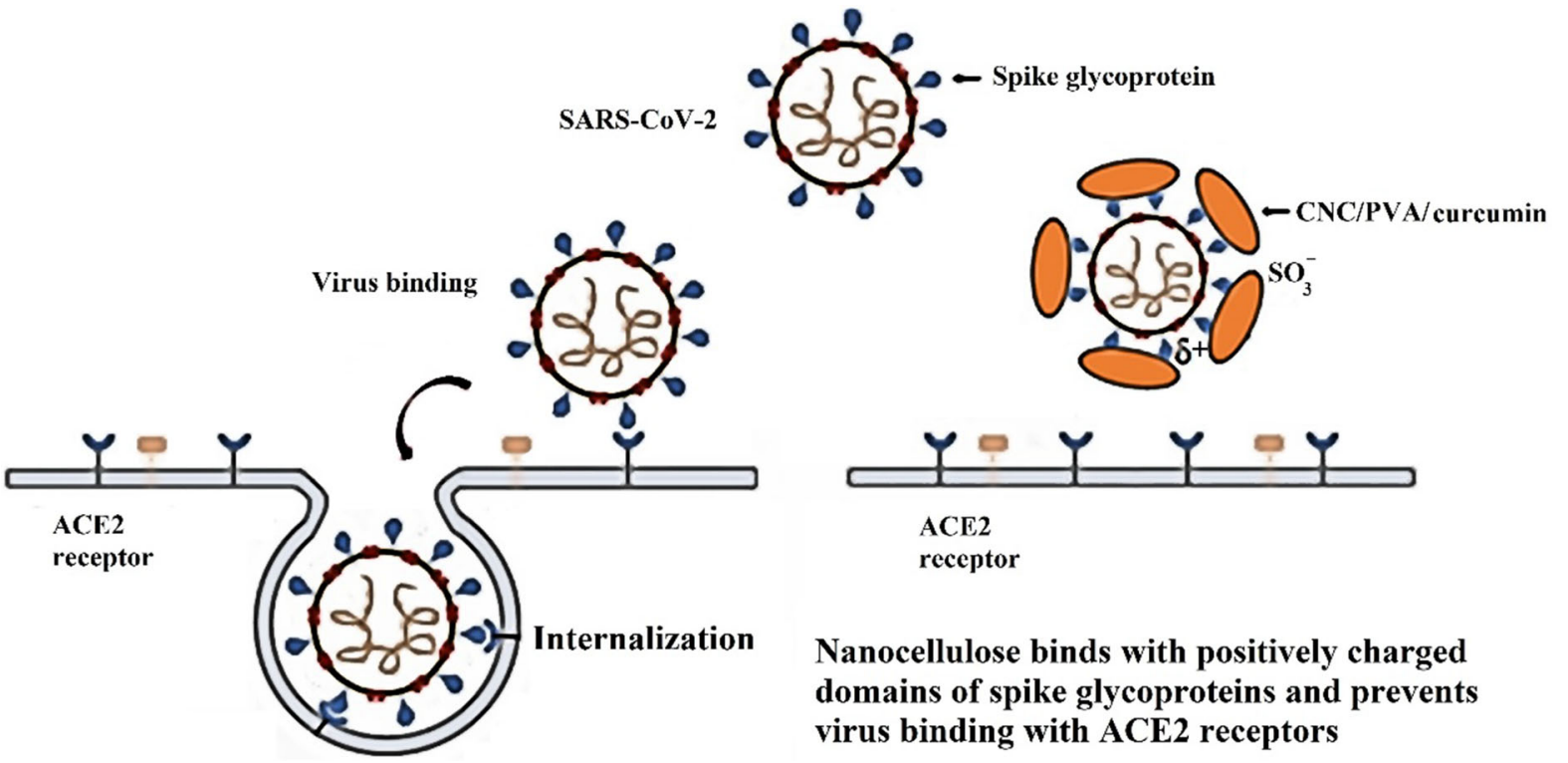

Fig. 4 The proposed inhibition mode of CNC/PVA/curcumin against SARS-CoV-2 infection 
to combat coronavirus infections in previous studies. For example, Chen et al. (2016) studied the antiviral efficacy of graphene oxide (GO) sheets and GO sheets with silver particles (GO-Ag) against feline coronavirus (FCoV). Results indicated that negatively charged GO sheets could interact with positive charge viral lipid membrane and cause disruption of the lipid membrane.

\section{Solubility studies}

Curcumin, a natural polyphenolic nutraceutical found in turmeric, has been linked to antioxidant, anticancer, anti-inflammatory, antiviral, and antibacterial properties; according to over 6000 citations, more than 100 clinical studies. Curcumin has been shown to have antiviral action against viruses such as the parainfluenza virus type 3 , feline infectious peritonitis virus, vesicular stomatitis virus, herpes simplex virus, flock house virus, and respiratory syncytial virus. Also, recent studies indicated that different formulations of curcumin could be used to treat COVID-19 successfully (Chen et al. 2020; Jena et al. 2021; Khaerunnisa et al. 2020; Manoharan et al. 2020; Saadat et al. 2020; Suravajhala et al. 2020; Zahedipour et al. 2020). Although curcumin exhibits diverse biological activities, its bioavailability has been restricted by its poor water solubility and fast presystemic metabolism. However, many attempts have been made to overcome their bioavailability limitations, including the development of curcumin-associated nanoparticles, liposomes, micellar formulations, cyclodextrin inclusion complexes, microemulsions, and surfactants (Petchsomrit et al. 2017; Ratanajiajaroen and Ohshima 2012; Sinjari et al. 2019; Udeni Gunathilake et al. 2017a, b; Zhang et al. 2016). With reference to our previous studies, we have used synthetic surfactant (Tween 20) and $\mathrm{pH}$-dependent water-soluble polymer (carboxymethyl cellulose) to enhance the solubility of curcumin (Ching et al. 2019; Gunathilake et al. 2020b). However, in this study, we are not using Tween 20 or carboxymethyl cellulose. The current research requires a more biocompatible biopolymer and possesses $\mathrm{pH}$-independent solubility properties to be used in the inhalable drug delivery system. Since the upper respiratory system is slightly acidic, if we use carboxymethyl cellulose, we will not be able to obtain enhanced solubility of curcumin because carboxymethyl cellulose is less ionizable in acidic conditions. Therefore, in this research, we are using PVA, a pH-independent aqueous soluble and biocompatible biopolymer, to improve curcumin solubility. We noticed that curcumin solubility increased from $2.85 \pm 0.06$ to $313.61 \pm 1.05 \mathrm{mg} / \mathrm{L}$ with increasing the PVA concentration from 0.05 to 0.8 (w/v\%) (Fig. 5). This is a considerable improvement in solubility compared to curcumin solubility in carboxymethyl cellulose medium in our previous study, which increased from $24 \pm 0.38 \mathrm{mg} / \mathrm{L}$ to $147 \pm 5.66 \mathrm{mg} / \mathrm{L}$ by increasing the carboxymethyl cellulose concentration from 0.1 to $2 \%$ (w/v) in PBS medium. In addition, the viscosity of the medium increased with increasing the carboxymethyl cellulose concentration in the previous study, which limited its addition to a certain extent to the medium. However, the addition of PVA did not considerably affect the viscosity of the medium; therefore the nanocelluloses were well dispersed in the PVA medium compared to the carboxymethyl cellulose medium (Gunathilake et al. 2020b). The physical appearance of the solubility of curcumin in the acidic medium with different concentrations of PVA is displayed in Fig. 6.

PVA is a water-soluble, biodegradable synthetic biopolymer. PVAs are categorized into different grades based on the degree of hydrolysis (the ratio of hydroxyl to acetyl groups) and the degree of polymerization, both of which affect water solubility (Kaiwen et al. 2016; Rahman et al. 2020). The physicochemical characteristics of PVA, such as hydration, dielectric constant, conformation, and dynamics, are affected by interactions between water

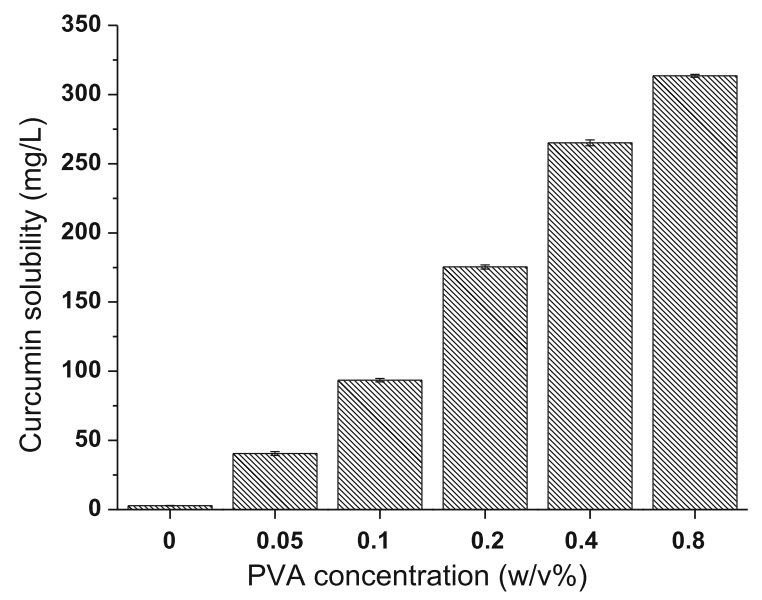

Fig. 5 Solubility of curcumin in acidic medium with different concentration of PVA 


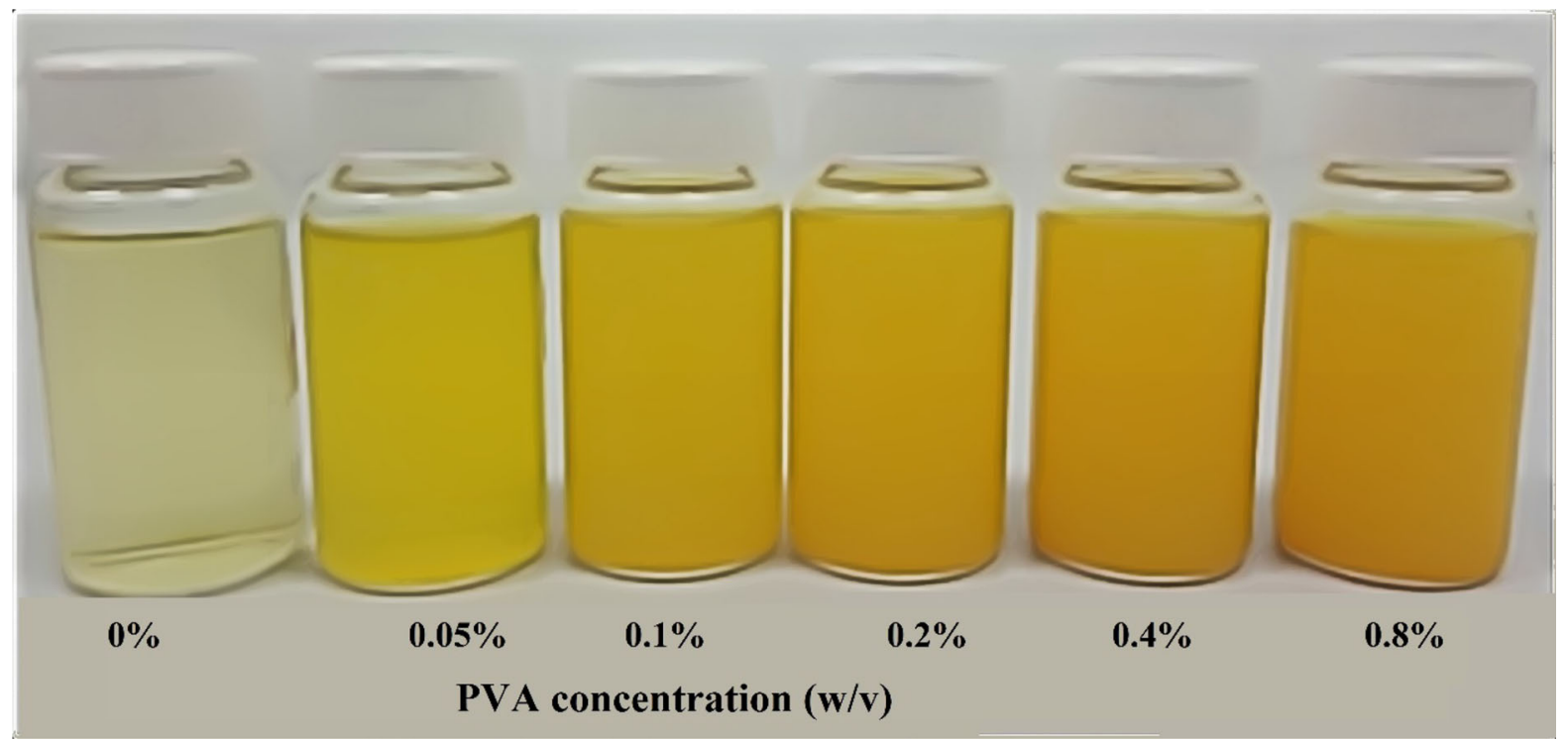

Fig. 6 Physical appearance of the solubility of curcumin in acidic medium with different concentrations of PVA

molecules and the -OH group of PVA in their aqueous solution. Since PVA contains both hydrophilic and hydrophobic groups, it will form a micelle-like structure and provide ideal conditions for the solubilization of weakly aqueous soluble curcumin. The formation of multiple stranded micelle-like structures contributes to changes in physical properties (Rahman et al. 2020). The rheological properties and adsorption characteristics at solid-liquid interfaces of these solutions vary from the aqueous medium. The polymer solubilized medium has a distinct microenvironment than the aqueous medium under which solubilization capabilities for sparingly soluble molecules with modified liquid-liquid interfacial tensions. Previous studies reported that the low molecular weight PVA showed a higher reduction of surface tension and faster dissolution in water. In addition, the lower degree of hydrolysis PVA polymer solubilized poor soluble drugs to a greater extent in water (Umemoto et al. 2020). In this study, we used low molecular weight PVA (78 kDa) with 87-89\% degree of hydrolysis. Umemoto et al. (2020) reported that the highest solubility of the poorly water-soluble drug (amenamevir) was obtained by the dissolution with a $66 \%$ degree of hydrolyzed PVA. The lowest solubility of amenamevir was shown by the dissolution with a $99 \%$ degree of hydrolyzed PVA. Meanwhile, PVAs with a hydrolysis degree not lower than $66 \%$ could be dissolved in water (Umemoto et al. 2020).
Drug loading capacity

As curcumin is poorly water-soluble, we used watersoluble synthetic polymer PVA as a surfactant to improve curcumin's solubility in the aqueous medium. First, the curcumin was dissolved in the PVA medium, and then nanocellulose was dispersed for the entrapment of curcumin. After the entrapment of curcumin and air-dried, the nanocellulose entrapped in PVA/ curcumin medium appeared in dark yellow, while the nanocellulose entrapped in aqueous curcumin medium (without PVA) seemed in light yellow (Fig. 7).

According to the UV-Vis analysis results, CNCs dispersed in curcumin, and PVA $0.8 \%$ solution showed the highest drug loading capacity, which was $8.90 \pm 0.2 \mathrm{mg} / \mathrm{g}$ (Fig. 8). The lowest drug loading capacity was shown by nanocellulose dispersed in the aqueous curcumin medium (without PVA), which was $0.40 \pm 0.01 \mathrm{mg} / \mathrm{g}$. The drug loading capacity increased by 22 -fold with the addition of $0.8 \%$ PVA to the aqueous curcumin medium. This study's drug loading capacity was slightly higher compared to the results of our previous study, in which we used Tween 20 as a surfactant for the dissolution of curcumin. The highest curcumin loading capacity was $7.73 \mathrm{mg} / \mathrm{g}$ in the previous study. This increase may be due to the less viscosity of PVA solution, providing better dispersion of nanocellulose than Tween 20 medium. 


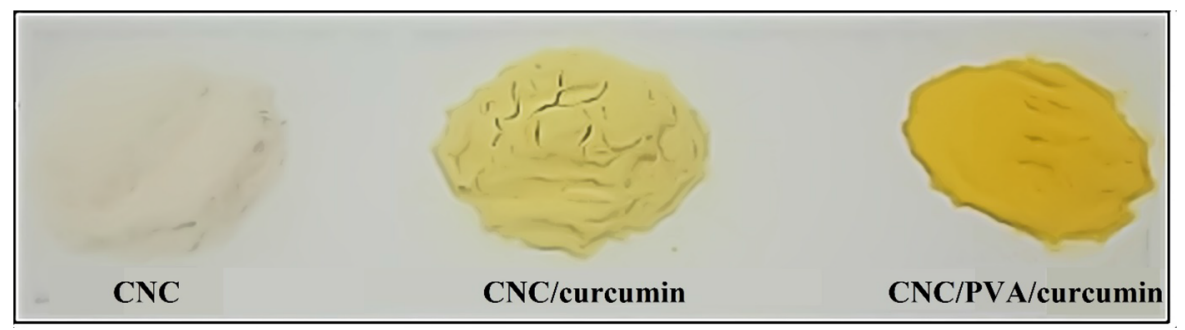

Fig. 7 Physical appearance of curcumin loaded CNC and PVA/curcumin loaded CNC

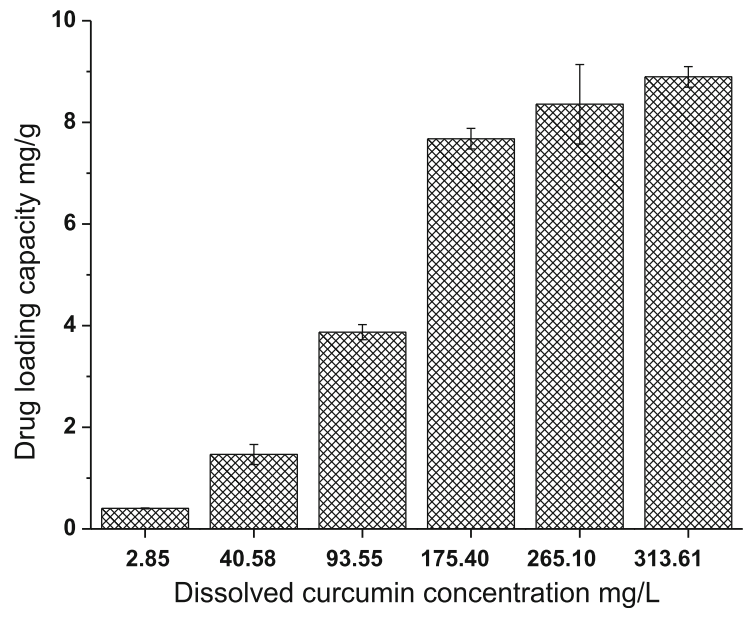

Fig. 8 Drug loading capacity of nanocellulose for curcumin dissolved with different concentrations of PVA

As PVA possessing the unique property of having both hydrophilic (hydroxyl) and hydrophobic (acetyl) groups, we predict that this polymer may develop a micelle-like structure and function as a polymeric surfactant. Many papers describe the development of polymer micelles as long-term circulating drug carriers. The polymeric micelles are incredibly fascinating because they trap hydrophobic drugs within their inner core and provide compact and flexible architectures. Polymeric micelles are formed at the critical micelle concentration in the aqueous medium due to the minimum energy state attainment. Umemoto et al. (2020) prepared PVA solutions with different PVA concentrations using PVAs of different hydrolysis degrees. The formation of the hydrophobic domain of the micelles was confirmed by the fluorescence intensity of pyrene emissions. Their results showed that the fluorescence emission intensity increased with increasing the PVA concentration. In addition, PVA with a lower degree of hydrolysis had lower critical micelle concentration. The $88 \%$ degree of hydrolyzed
PVA showed critical micelle concentration at around $0.5 \%(\mathrm{w} / \mathrm{v})$. Besides, the polymers like hydroxypropylmethylcellulose did not show an increase of fluorescence intensity with increasing its concentration. Our study used a $0.05-0.8 \%$ (w/v) PVA concentration range and $87-89 \%$ degree of hydrolyzed PVA for the dissolution of curcumin. This range is within the critical micelle concentration range of the $88 \%$ degree of hydrolyzed PVA mentioned in the previous study.

The adsorption of polymeric micelles is a feasible method to enhance the compatibility of the hydrophilic nanocellulose with the hydrophobic drug curcumin. The PVA micelles' hydrophilic domain may have an affinity for adsorption to cellulose due to its hydroxyl groups. However, not all CNC hydroxyls are accessible. Some of them are oriented towards the integral parts of nanocellulose. According to previous studies, only one half of the hydroxyls present in CNC are reactive (Akhlaghi et al. 2019). Higher drug loading capacity is necessary to ensure that the required drug dose at the target site is available to decrease drug resistance development. Furthermore, the targeted delivery of nanotherapeutics directly to the target site also increases the efficacy of the drug. As $\mathrm{CNC} / \mathrm{PVA}$ /curcumin particles full fill both these conditions, we believe that this nanotherapeutic's inhalation delivery will provide a successful approach for treating the initial stages of COVID -19. Furthermore, the surfactant molecule's hydrophilic end may adsorb on the surface of cellulose nanoparticles, while the hydrophobic end may extend out, producing a nonpolar surface and reducing the nanoparticle's surface tension. The presence of PVA micelles' hydrophobic ends on the surface of nanocellulose will decrease the interaction of water molecules with nanocellulose. Therefore, the hydrolytic degradation of nanocellulose will decrease, and the stability of nanocellulose in an aqueous medium will increase. In previous studies, the 
presence of these hydrophobic groups has rendered the polymers with lower water uptake properties and decreased hydrolytic degradation (Elmowafy et al. 2019).

In vitro drug release

The drug release was carried out in an acidic medium which is similar to the mucosal airway $\mathrm{pH}$. Compared with blood and interstitial $\mathrm{pH}$ of 7.4, mucosal airway $\mathrm{pH}$ is considered acidic (Fischer and Widdicombe 2006). In the meantime, curcumin is stable in an acidic medium (85-95\%) but unstable in neutral or alkaline solutions (53-62\%) (Kharat et al. 2017). The stability of curcumin in acidic environments is possibly due to its conjugated diene, which is gradually destroyed when the $\mathrm{H}^{+}$is removed at alkaline $\mathrm{pH}$ during dissociation of phenolic groups, leading to more prone positioning to degradation (Lee et al. 2013). Therefore, it is good to use curcumin as an antiviral agent in the acidic medium. Furthermore, it was reported that the curcumin was more stable in the emulsions under acidic $\mathrm{pH}$ conditions. Moreover, the curcumin was less prone to crystallize in the emulsions than in the aqueous solutions because curcumin has a much higher solubility in oil than in water. Similarly, the high solubility of curcumin in acidic surfactant (PVA) of this study will decrease the crystallization and increase curcumin's stability. In addition, previous studies investigated the storage stability of curcumin at $37{ }^{\circ} \mathrm{C}$ (body temperature) for 31 days. Also, no major visual distinction could be made between fresh and stored curcumin emulsions, demonstrating that the curcumin in the emulsions was reasonably stable under the storage conditions used (Kharat et al. 2017).

All the formulations displayed initial burst release within the first 30 min owing to the fraction of the drug attached weekly to the large surface area of CNCs. After that, all the formulations showed sustained drug release profiles. As shown in Fig. 9, among all the formulations, CNC/PVA0.8/curcumin showed the highest drug release of $17.11 \pm 0.22 \mathrm{mg} / \mathrm{L}$ and $\mathrm{CNC} / \mathrm{PVA} 0 /$ curcumin showed the lowest drug release of $1.25 \pm 0.15 \mathrm{mg} / \mathrm{L}$ at around $390 \mathrm{~min}$. It can be seen that the drug release increased with increasing the PVA concentration in the drug-loaded medium. This may be due to the improvement of drug loading and the increase of adsorption of PVA to nanocellulose with increasing the PVA concentration in the medium.
The presence of a shoulder-type peak proved the attachment of PVA into nanocellulose at around $1730 \mathrm{~cm}^{-1}$ of CNC/PVA/curcumin FTIR spectrum. This PVA facilitates improving the curcumin solubility in the aqueous medium by forming polymer micelles and adsorbing the hydrophobic curcumin into the core of the micelle structure. PVA is a nonionic $\mathrm{pH}$-independent water-soluble polymer, which is supposed to have the same solubilization performance regardless of the $\mathrm{pH}$ of the medium. Thereby, it will improve the solubility of the curcumin even in the acidic medium due to the interactions of the micelle's hydrophilic domain with water molecules.

Most of the reported work relevant to burst release in the pharmaceutical field focused on avoiding it from controlled release formulations. Initial burst release is disadvantageous because the initial high release rates can lead to drug doses near or above the in vivo toxic level and may be metabolized and excreted without achieving its therapeutic effect. However, in several cases, such as in targeted delivery systems, where the delivery location is highly specific, burst release may be desired at that site. In this research, the inhalable curcumin loaded nanoparticles will be delivered to the respiratory mucosal airway to treat the initial stages of SARS-CoV-2. Therefore, the initial high release rates may be advantageous as nanoparticles directly contacting the viral invaded tissues. Also, curcumin is non-toxic even at a relatively high concentration. It showed no lethal effect on healthy organs at doses as high as $8 \mathrm{~g}$ /day (Almosa et al. 2020).

The poor solubility of curcumin causes low in vivo bioavailability. For example, ingestion of $12 \mathrm{~g}$ of curcumin resulted in $29.7 \mathrm{ng} / \mathrm{mL}(\sim 81 \mathrm{nM})$ of curcumin in human blood serum after one-hour ingestion that is far below any of the therapeutic levels identified in several in vitro studies. Previous studies concerning the antiviral activity of curcumin against RNA viruses reporting that curcumin is needed at an $\mathrm{IC}_{50}$ of $40 \mu \mathrm{M}$ to inhibit the HIV-1 integrase (Mazumder et al. 1995), effective dose against influenza $\mathrm{A}$ virus (IAV) is $\sim 10 \mu \mathrm{M}$ (Chen et al. 2010), for Zika Virus $\mathrm{IC}_{50}$ is $\sim 5-14 \mu \mathrm{M}$ (Gao et al. 2019), for dengue virus $\mathrm{IC}_{50}$ is $\sim 36-66 \mu \mathrm{M}$ (Balasubramanian et al. 2019) for chikungunya virus $\mathrm{IC}_{50}$ is $10.79 \mu \mathrm{M}$ (von Rhein et al. 2016), for vesicular stomatitis virus $\mathrm{IC}_{50}$ is $4.5 \mu \mathrm{M}$ (Mounce et al. 2017; von Rhein et al. 2016) for influenza $A$ virus IC $_{50}$ is $\sim 0.2 \mu \mathrm{M}$ (Richart et al. 2018) for transmissible 
Fig. 9 In vitro drug release from different formulations of $\mathrm{CNC} / \mathrm{PVA} /$ curcumin

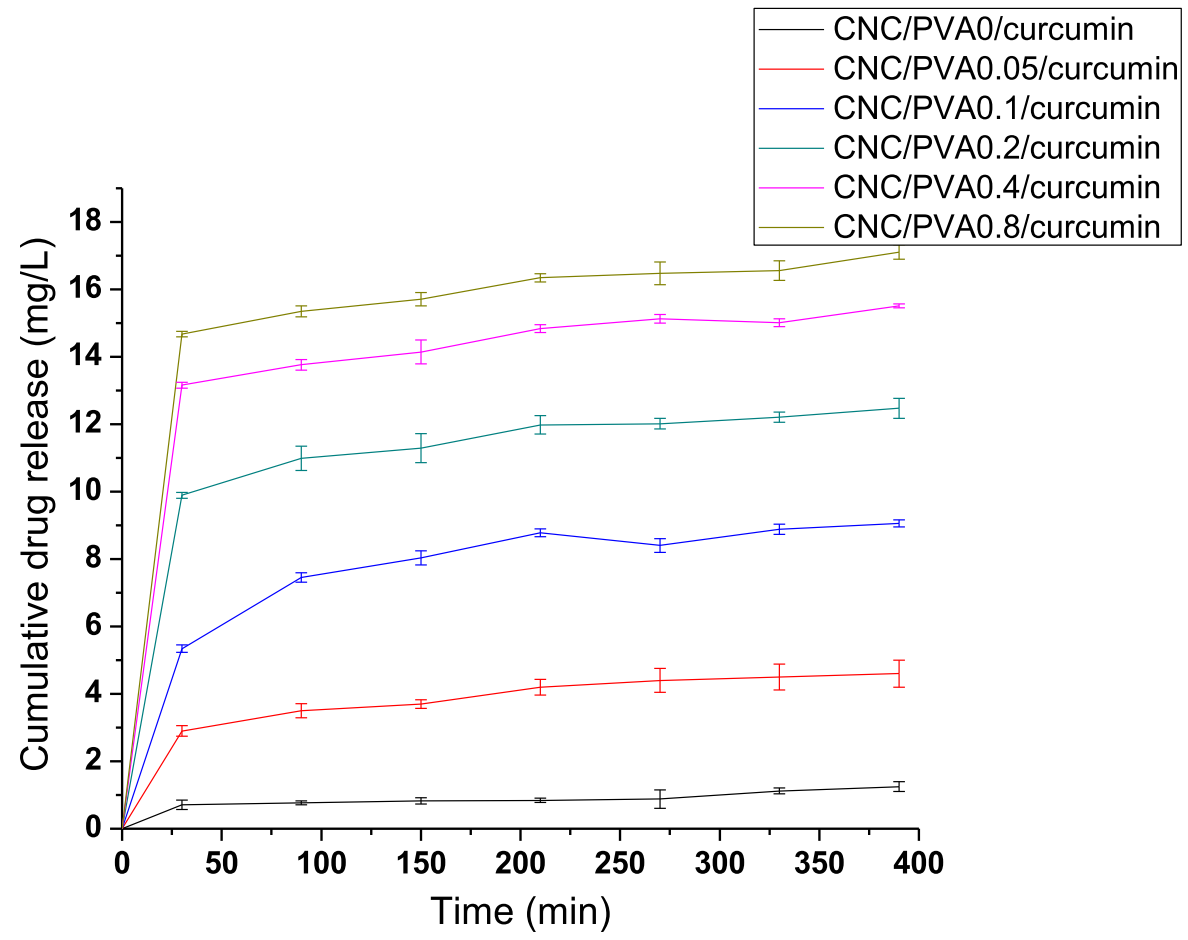

Drug activity

The chemical reactions that correspond to the biological activities of the drug have been the most significant factor to be considered when choosing carriers for drug delivery. Drugs deteriorate in certain drug delivery systems due to adverse interactions with carrier molecules. To overcome such incidences, the carrier must be resistant to deteriorative reactions with the therapeutic agent and be able to deliver it to the particular site of the body without chemical changes. The degradation reactions caused by destructive interactions of drug and carrier molecules can be assessed using the UV-Vis spectra of pure drug and the drug released from the delivery carrier (Bashir et al. 2016). Curcumin contains three reactive functional groups linked with its various biological functions, as determined by its FTIR spectrum: one diketone moiety and two phenolic groups. Important chemical reactions related to its biological activity include the existence of $\mathrm{C}=\mathrm{O}$ groups as hydrogen acceptors and C-4 as a hydrogen donor. These functional groups will also contribute to the antiviral properties of curcumin (Ahmed et al. 2017). In the UV-Vis spectrum, curcumin showed a strong absorption peak at $422 \mathrm{~nm}$ due to the low-energy $\pi-\pi *$ 
chromophore excitation formed by the enolization of the diketone and its conjugation with vinylguaiacol's p-electron clouds (Zsila et al. 2004). In this study, the drug (curcumn) is in contact with PVA, nanocellulose and acidic medium. Figure 10 shows the UV-Vis spectra of the pure drug (curcumin) and release drug from $\mathrm{CNC} / \mathrm{PVA} /$ curcumin nanoparticles into the acidic medium. It can be seen that the $422 \mathrm{~nm}$ peak in both spectra remained intact, with no movement in the spectrum's upward or downward direction. Hence, it can be concluded that the functional groups of curcumin, which corresponds to its therapeutic properties were preserved without any degradative reaction with CNC, PVA or released acidic medium.

Future studies will be focused on the determination of the antiviral activity of CNC/PVA/curcumin nanoparticles against SARS-CoV-2. In research and clinical contexts, combined reverse transcription polymerase chain reaction (RT-PCR) and quantitative PCR (qPCR) are frequently used for gene expression profiling and viral RNA quantification. In future studies, real-time quantitative PCR (qRT-PCR) will be used to determine the antiviral activity of $\mathrm{CNC} /$ $\mathrm{PVA} /$ curcumin against SARS-CoV-2. The decrease in viral titer of coronavirus-infected cells will be used to assess antiviral efficacy (Freeman et al. 1999; Keyaerts et al. 2009).

The main advantages of inhaled medications are the delivery of drug directly into the airways, greater local concentrations, and a lower chance of systemic adverse effects. However, incidences of side effects

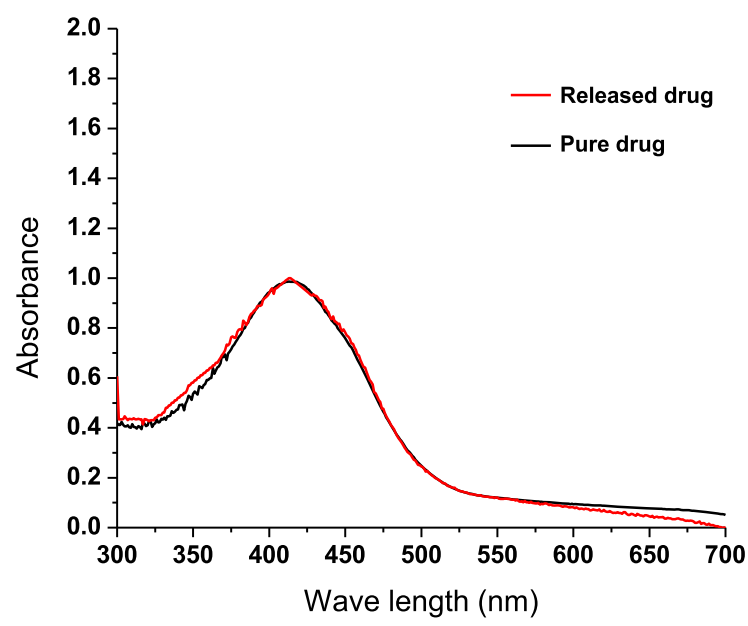

Fig. 10 UV-Vis spectra of pure curcumin and curcumin released from nanocellulose into acidic medium from some inhaled drugs depositing locally in the oropharynx and larynx have been reported. The frequency of complaints is determined by the type of drugs, dosage, administration frequency, inhaler method, and delivery mechanism. Dysphonia (a hoarse voice) is a common complaint among glucocorticoid inhaler users. But it was reported that hydrofluoroalkane inhalers have a lower risk for dysphonia than older chlorofluorocarbon inhalers. Also, the risk of dysphonia may be lower with budesonide dry powder inhaler compared with chlorofluorocarbon or fluticasone propionate dry powder inhalers (Saag et al. 2015). In addition, cough is an adverse effect associated with dry powder inhalers that may hinder the delivery of drugs into the lungs. Controlling the particle size of the formulation to $<5 \mu \mathrm{m}$ is required to reduce cough and ensure that the particles land in the deep lung, where cough receptors are absent. However, such an approach would need to consider the site of therapeutic action (Chang et al. 2020). A carrier material is required in most powder-dispensing devices. This vehicle material is combined with the medication to help the powder flow through the device more easily. Lactose and glucose are two types of the carriers utilized in powder-dispensing devices. Even though these substances are substantially greater than the drug (98\% or more), allergic reactions to lactose and glucose appear to be fewer (Laube and Dolovich 2014). The acute inhalation toxicity of nanocellulose has been investigated in previous studies. Endes et al. (2014) investigated nebulized concentrations of $\mathrm{CNC}$ from 0.14 to $1.57 \mu \mathrm{g} / \mathrm{cm}^{2}$ and found no significant cytotoxicity in 3D human airway barrier model. In another study, Lopes et al. (2017) found that cellulose nanofiber exposure did not induce cytotoxicity in any of the cell lines (human dermal, lung, and immune cells) examined up to $500 \mu \mathrm{g} / \mathrm{mL}$ for $24 \mathrm{~h}$ of exposure.

In addition to determining the antiviral activity of $\mathrm{CNC} / \mathrm{PVA}$ /curcumin nanoparticles, the toxicity of the $\mathrm{CNC} / \mathrm{PVA}$ /curcumin complex on human airway cells from various parts of the respiratory tract will be investigated with different concentrations of $\mathrm{CNC} /$ $\mathrm{PVA} /$ curcumin in the future studies. This will be based on the cell culture studies of primary human airway epithelial cells, cell viability assay studies and cell morphological investigations (Ferreira Lopes et al. 2017; Loutfy et al. 2020). 


\section{Conclusion}

In this study, CNC/PVA/curcumin nanoparticles were prepared with enhanced drug loading properties. The possibility of its use as an inhalable nanotherapeutic to treat the SARS-CoV-2 was discussed. The extracted nanocellulose showed more densely packed fibrous networks with a diameter ranged from 50 to $100 \mathrm{~nm}$. The extracted curcumin was characterized by FTIR spectroscopy and showed characteristic peaks similar to those obtained by previous studies and commercial curcumin. The solubility of curcumin increased from $2.85 \pm 0.06$ to $313.61 \pm 1.05 \mathrm{mg} / \mathrm{L}$ with increasing the PVA concentration from 0.05 to $0.8(\mathrm{w} / \mathrm{v} \%)$ in acidic medium. This was a considerable improvement compared to the use of carboxymethyl cellulose in our previous study. Also, PVA does not affect the viscosity of the medium and the dispersibility of nanocellulose. The drug loading capacity of CNCs increased up to $8.90 \pm 0.2 \mathrm{mg} / \mathrm{g}$ with the addition of $0.8 \%$ PVA to the drug loading medium, which was a 22-fold increase compared to the aqueous curcumin medium. All the formulations showed initial burst release, and the highest drug release showed by $\mathrm{CNC}$ / PVA0.8/curcumin formulation, which was $17.11 \pm 0.22 \mathrm{mg} / \mathrm{L}$ at around $390 \mathrm{~min}$. Drug activity studies showed that the functional groups of curcumin, which corresponds to its therapeutic properties, preserved without any degradative reaction with $\mathrm{CNC}$, PVA or released acidic medium. According to the results, we believe that the CNCs' morphology, surface characteristics, well-reported curcumin antiviral activity, and enhanced drug loading capacity will provide these formulations a suitable candidate for designing antiviral nanotherapeutics against SARSCoV-2. This study highlights in vitro studies and future studies of these formulations will focus on determining the antiviral activity of CNC/PVA/curcumin nanoparticles against SARS-CoV-2.

Acknowledgments The authors would like to acknowledge the financial support from the AUN/SEED-Net Special Program for Research Against COVID-19 (SPRAC): IF068-2020 and University Malaya research grant: ST058-2021, and GPF 002A2019 for the success of this project.

\section{Declarations}

Conflict of interest The authors declared no conflict of interest.
Human and animal rights This manuscript does not contain any studies with human participants or animals performed by any of the authors.

\section{References}

Aguayo MG, Fernández Pérez A, Reyes G, Oviedo C, Gacitúa W, Gonzalez R, Uyarte O (2018) Isolation and characterization of cellulose nanocrystals from rejected fibers originated in the kraft pulping process. Polymers 10:1145

Ahmed M, Qadir MA, Shafiq MI, Muddassar M, Hameed A, Arshad MN, Asiri AM (2017) Curcumin: synthesis optimization and in silico interaction with cyclin dependent kinase. Acta Pharm 67:385-395

Akhlaghi SP, Tam KC, Berry RM (2019) Surface modified nanocrystalline cellulose and uses thereof. Google Patents,

Almosa H, Alqriqri M, Denetiu I, Baghdadi MA, Alkhaled M, Alhosin M, Aldajani WA, Zamzami M, Ucisik MH, Damiati S (2020) Cytotoxicity of standardized curcuminoids mixture against epithelial ovarian cancer cell line SKOV-3. Sci Pharm 88:11

Avasarala S, Zhang F, Liu G, Wang R, London SD, London L (2013) Curcumin modulates the inflammatory response and inhibits subsequent fibrosis in a mouse model of viralinduced acute respiratory distress syndrome. PLOS ONE 8:e57285

Balasubramanian A, Pilankatta R, Teramoto T, Sajith AM, Nwulia E, Kulkarni A, Padmanabhan R (2019) Inhibition of dengue virus by curcuminoids. Antiviral Res 162:71-78

Bar-On YM, Flamholz A, Phillips R, Milo R (2020) Science Forum: SARS-CoV-2 (COVID-19) by the numbers. Elife 9:57309

Bashir S, Teo YY, Ramesh S, Ramesh K (2016) Synthesis, characterization, properties of $\mathrm{N}$-succinyl chitosan-g-poly (methacrylic acid) hydrogels and in vitro release of theophylline. Polymer 92:36-49

Bich VT, Thuy NT, Binh NT, Huong NTM, Yen PND, Luong TT (2009) Structural and spectral properties of curcumin and metal-curcumin complex derived from turmeric (Curcuma longa). In: Physics and engineering of new materials. Springer, pp 271-278

Chang RYK, Kwok PCL, Ghassabian S, Brannan JD, Koskela HO, Chan HK (2020) Cough as an adverse effect on inhalation pharmaceutical products. $\mathrm{Br} \mathrm{J}$ Pharmacol 177:4096-4112

Chen B, Zhang D-P, Gao W (2008) Effect of curcumin on the expression of collagen type I protein and transforming growth factor-beta1 mRNA in pulmonary fibrosis rats. Chin J Ind Hyg Occup Dis 26:257-261

Chen D-Y, Shien J-H, Tiley L, Chiou S-S, Wang S-Y, Chang T-J, Lee Y-J, Chan K-W, Hsu W-L (2010) Curcumin inhibits influenza virus infection and haemagglutination activity. Food Chem 119:1346-1351

Chen L, Hu C, Hood M, Zhang X, Zhang L, Kan J, Du J (2020) A novel combination of vitamin $\mathrm{C}$, curcumin and glycyrrhizic acid potentially regulates immune and inflammatory response associated with coronavirus infections: a perspective from system biology analysis. Nutrients 12:1193 
Chen Y-N, Hsueh Y-H, Hsieh C-T, Tzou D-Y, Chang P-L (2016) Antiviral activity of graphene-silver nanocomposites against non-enveloped and enveloped viruses. Int $\mathbf{J}$ Environ Res Public Health 13:430

Ching YC, Gunathilake TMS, Chuah CH, Ching KY, Singh R, Liou N-S (2019) Curcumin/Tween 20-incorporated cellulose nanoparticles with enhanced curcumin solubility for nano-drug delivery: characterization and in vitro evaluation. Cellulose 26:5467-5481

Cutroneo KR, White SL, Phan SH, Ehrlich HP (2007) Therapies for bleomycin induced lung fibrosis through regulation of TGF- $\beta 1$ induced collagen gene expression. J Cell Physiol 211:585-589

Dai J, Gu L, Su Y, Wang Q, Zhao Y, Chen X, Deng H, Li W, Wang G, Li K (2018) Inhibition of curcumin on influenza A virus infection and influenzal pneumonia via oxidative stress, TLR2/4, p38/JNK MAPK and NF-кB pathways. Int Immunopharmacol 54:177-187

Dandapat J, Jena A, Kanungo N, Nayak V, Chainy G (2020) Catechin and Curcumin interact with corona (2019-nCoV/ SARS-CoV2) viral S protein and ACE2 of human cell membrane: insights from Computational study and implication for intervention. Sci Rep 11(1):2043. https://doi.org/ 10.1038/s41598-021-81462-7

Elmowafy EM, Tiboni M, Soliman ME (2019) Biocompatibility, biodegradation and biomedical applications of poly (lactic acid)/poly (lactic-co-glycolic acid) micro and nanoparticles. J Pharm Investig 49:347-380

Emirik M (2020) Potential therapeutic effect of turmeric contents against SARS-CoV-2 compared with experimental COVID-19 therapies: in silico study. J Biomol Struct Dyn 1-14. https://doi.org/10.1080/07391102.2020.1835719

Endes C, Schmid O, Kinnear C, Mueller S, Camarero-Espinosa S, Vanhecke D, Foster EJ, Petri-Fink A, Rothen-Rutishauser B, Weder C (2014) An in vitro testing strategy towards mimicking the inhalation of high aspect ratio nanoparticles. Part Fibre Toxicol 11:1-13

Endes C, Mueller S, Kinnear C, Vanhecke D, Foster EJ, PetriFink A, Weder C, Clift MJ, Rothen-Rutishauser B (2015) Fate of cellulose nanocrystal aerosols deposited on the lung cell surface in vitro. Biomacromol 16:1267-1275

Ferreira Lopes S, Vacher G, Ciarlo E, Savova-Bianchi D, Roger T, Niculita-Hirzel H (2017) Primary and immortalized human respiratory cells display different patterns of cytotoxicity and cytokine release upon exposure to deoxynivalenol, nivalenol and fusarenon-X. Toxins 9:337

Ferreira VH, Nazli A, Dizzell SE, Mueller K, Kaushic C (2015) The anti-inflammatory activity of curcumin protects the genital mucosal epithelial barrier from disruption and blocks replication of HIV-1 and HSV-2. PLoS ONE 10:e 0124903

Fischer H, Widdicombe JH (2006) Mechanisms of acid and base secretion by the airway epithelium. J Membr Biol 211:139-150

Freeman WM, Walker SJ, Vrana K (1999) Quantitative RTPCR: pitfalls and potential. Biotechniques 26:112-125

Fugita R, Gálico D, Guerra R, Perpétuo G, Treu-Filho O, Galhiane M, Mendes R, Bannach G (2012) Thermal behaviour of curcumin. Braz J Therm Anal 1:19-23

Gao Y, Tai W, Wang N, Li X, Jiang S, Debnath AK, Du L, Chen $S$ (2019) Identification of novel natural products as effective and broad-spectrum anti-Zika virus inhibitors. Viruses 11:1019

Gunathilake TMSU, Ching YC, Chuah CH, Abd Rahman N, Nai-Shang L (2020a) Recent advances in celluloses and their hybrids for stimuli-responsive drug delivery. Int $\mathrm{J}$ Biol Macromol 158:670-688

Gunathilake TMSU, Ching YC, Chuah CH, Abd Rahman N, Nai-Shang L (2020b) pH-responsive poly (lactic acid)/sodium carboxymethyl cellulose film for enhanced delivery of curcumin in vitro. J Drug Deliv Sci Technol 58:101787

Gunathilake TMSU, Ching YC, Chuah CH, Illias HA, Ching KY, Singh R, Nai-Shang L (2018) Influence of a nonionic surfactant on curcumin delivery of nanocellulose reinforced chitosan hydrogel. Int $\mathrm{J}$ Biol Macromol 118:1055-1064

Hassanzadeh K, Perez Pena H, Dragotto J, Buccarello L, Iorio F, Pieraccini S, Sancini G, Feligioni M (2020) Considerations around the SARS-CoV-2 Spike Protein with particular attention to COVID-19 brain infection and neurological symptoms. ACS Chem Neurosci 11:2361-2369

Jena AB, Kanungo N, Nayak V, Chainy G, Dandapat J (2021) Catechin and Curcumin interact with corona (2019-nCoV/ SARS-CoV2) viral S protein and ACE2 of human cell membrane: insights from Computational study and implication for intervention. Sci Rep 11(1):2043. https://doi.org/ 10.1038/s41598-021-81462-7

Kaiwen C, Ching YC, Chuah CH, Sabariah J, Nai-Shang L (2016) preparation and characterization of polyvinyl alcohol-chitosan composite films reinforced with cellulose nanofiber. Materials 9:644

Kharat M, Du Z, Zhang G, McClements DJ (2017) Physical and chemical stability of curcumin in aqueous solutions and emulsions: impact of $\mathrm{pH}$, temperature, and molecular environment. J Agric Food Chem 65:1525-1532

Keyaerts E, Li S, Vijgen L, Rysman E, Verbeeck J, Van Ranst M, Maes P (2009) Antiviral activity of chloroquine against human coronavirus OC43 infection in newborn mice. Antimicrob Agents Chemother 53:3416-3421

Khaerunnisa S, Kurniawan H, Awaluddin R, Suhartati S, Soetjipto S (2020) Potential inhibitor of COVID-19 main protease (Mpro) from several medicinal plant compounds by molecular docking study. Pharmacol Toxicol. https://doi. org/10.20944/preprints202003.0226.v1

Kovacs T, Naish V, O’Connor B, Blaise C, Gagné F, Hall L, Trudeau V, Martel P (2010) An ecotoxicological characterization of nanocrystalline cellulose (NCC). Nanotoxicology 4:255-270

Larsen RW, Zielke P, Suhm MA (2007) Hydrogen-bonded OH stretching modes of methanol clusters: a combined IR and Raman isotopomer study. J Chem Phys 126:194307

Laube BL, Dolovich MB (2014) Aerosols and aerosol drug delivery systems. In: Middleton's allergy: principles and practice: Eighth Edition. Elsevier Inc., pp 1066-1082

Lee W-H, Loo C-Y, Bebawy M, Luk F, Mason RS, Rohanizadeh R (2013) Curcumin and its derivatives: their application in neuropharmacology and neuroscience in the 21st century. Curr Neuropharmacol 11:338-378

Li X, Fang Q, Tian X, Wang X, Ao Q, Hou W, Tong H, Fan J, Bai S (2017) Curcumin attenuates the development of 
thoracic aortic aneurysm by inhibiting VEGF expression and inflammation. Mol Med Rep 16:4455-4462

Li Y, Wang J, Liu Y, Luo X, Lei W, Xie L (2020) Antiviral and virucidal effects of curcumin on transmissible gastroenteritis virus in vitro. J Gen Virol 101:1079-1084

Lopes VR, Sanchez-Martinez C, Strømme M, Ferraz N (2017) In vitro biological responses to nanofibrillated cellulose by human dermal, lung and immune cells: surface chemistry aspect. Part Fibre Toxicol 14:1-13

Loutfy SA, Elberry MH, Farroh KY, Mohamed HT, Mohamed AA, Mohamed EB, Faraag AHI, Mousa SA (2020) Antiviral activity of chitosan nanoparticles encapsulating curcumin against hepatitis $\mathrm{C}$ virus genotype $4 \mathrm{a}$ in human hepatoma cell lines. Int J Nanomed 15:2699

Mahmud A, Discher DE (2011) Lung vascular targeting through inhalation delivery: insight from filamentous viruses and other shapes. IUBMB Life 63:607-612

Manoharan Y, Haridas V, Vasanthakumar K, Muthu S, Thavoorullah FF, Shetty P (2020) Curcumin: a wonder drug as a preventive measure for COVID19 management. Indian J Clin Biochem 35:373-375

Mathew T, Sarada S (2015) Attenuation of NFkB activation augments alveolar transport proteins expression and activity under hypoxia. IJSR 4:2230-2237

Mazumder A, Raghavan K, Weinstein J, Kohn KW, Pommier Y (1995) Inhibition of human immunodeficiency virus type-1 integrase by curcumin. Biochem Pharmacol 49:1165-1170

Menon JU, Ravikumar P, Pise A, Gyawali D, Hsia CC, Nguyen KT (2014) Polymeric nanoparticles for pulmonary protein and DNA delivery. Acta Biomater 10:2643-2652

Mounce BC, Cesaro T, Carrau L, Vallet T, Vignuzzi M (2017) Curcumin inhibits Zika and chikungunya virus infection by inhibiting cell binding. Antiviral Res 142:148-157

Muralidharan P, Malapit M, Mallory E, Hayes D Jr, Mansour HM (2015) Inhalable nanoparticulate powders for respiratory delivery. Nanomed Nanomed-Nanotechnol 11:1189-1199

Nascimento P, Marim R, Carvalho G, Mali S (2016) Nanocellulose produced from rice hulls and its effect on the properties of biodegradable starch films. Mat Res 19:167-174

Olsson A-M, Salmén L (2004) The association of water to cellulose and hemicellulose in paper examined by FTIR spectroscopy. Carbohydr Res 339:813-818

WHO (2021) COVID-19 Weekly Epidemiological Update, 7 February $2021 \mathrm{WHO}$

Patra JK, Das G, Fraceto LF, Campos EVR, del Pilar R-T, Acosta-Torres LS, Diaz-Torres LA, Grillo R, Swamy MK, Sharma S (2018) Nano based drug delivery systems: recent developments and future prospects. J Nanobiotechnol 16:1-33

Petchsomrit A, Sermkaew N, Wiwattanapatapee R (2017) Alginate-based composite sponges as gastroretentive carriers for curcumin-loaded self-microemulsifying drug delivery systems. Sci Pharm 85:11

Punithavathi D, Venkatesan N, Babu M (2000) Curcumin inhibition of bleomycin-induced pulmonary fibrosis in rats. Br J Pharmacol 131:169-172

Punithavathi D, Venkatesan N, Babu M (2003) Protective effects of curcumin against amiodarone-induced pulmonary fibrosis in rats. Br J Pharmacol 139:1342-1350
Rahman F, Rafiquee M (2020) Studies on the hydration behavior of polyvinyl alcohol in aqueous solution: a kinetic approach through the hydrolysis of benzocaine. JSD 23:471-480

Ratanajiajaroen P, Ohshima M (2012) Synthesis, release ability and bioactivity evaluation of chitin beads incorporated with curcumin for drug delivery applications. J Microencapsul 29:549-558

Richart SM, Li Y-L, Mizushina Y, Chang Y-Y, Chung T-Y, Chen G-H, Tzen JT-C, Shia K-S, Hsu W-L (2018) Synergic effect of curcumin and its structural analogue (Monoacetylcurcumin) on anti-influenza virus infection. J Food Drug Anal 26:1015-1023

Roman M, Winter WT (2004) Effect of sulfate groups from sulfuric acid hydrolysis on the thermal degradation behavior of bacterial cellulose. Biomacromol 5:1671-1677

Saadat S, Mansoor S, Naqvi N, Fahim A, Rehman Z, Khan SY, Saadat S (2020) Structure based drug discovery by virtual screening of 3699 compounds against the crystal structures of six key SARS-CoV-2 proteins. Res Sq. https://doi.org/ 10.21203/rs.3.rs-28113/v1

Saag KG, Furst DE, Barnes PJ (2015) Major side effects of inhaled glucocorticoids. UpToDate 19

Sagi S, Mathew T, Patir H (2014) Prophylactic administration of curcumin abates the incidence of hypobaric hypoxia induced pulmonary edema in rats: a molecular approach. Int J Respir Pulm Med 4:1000164

Sahebkar A, Henrotin Y (2016) Analgesic efficacy and safety of curcuminoids in clinical practice: a systematic review and meta-analysis of randomized controlled trials. Pain Med 17:1192-1202

Sajjad W, He F, Ullah MW, Ikram M, Shah SM, Khan R, Khan T, Khalid A, Yang G, Wahid F (2020) Fabrication of bacterial cellulose-curcumin nanocomposite as a novel dressing for partial thickness skin burn. Front Bioeng Biotechnol 8:553037. https://doi.org/10.3389/fbioe.2020. 553037

Salabei JK, Conklin DJ (2013) Cardiovascular autophagy: crossroads of pathology, pharmacology and toxicology Cardiovasc. Toxicol 13:220-229

Sampath UTM, Ching YC, Chuah CH, Singh R, Lin P-C (2017) Preparation and characterization of nanocellulose reinforced semi-interpenetrating polymer network of chitosan hydrogel. Cellulose 24:2215-2228

Sarkar S (2020) Silver nanoparticles with bronchodilators through nebulisation to treat COVID 19 patients. Curr Med Res Opin 3:449-450

Schoof M, Faust B, Saunders RA, Sangwan S, Rezelj V, Hoppe N, Boone M, Billesbølle CB, Puchades C, Azumaya CM (2020) An ultrapotent synthetic nanobody neutralizes SARS-CoV-2 by stabilizing inactive. Spike Sci 370:1473-1479

Septevani AA, Annamalai PK, Martin DJ Synthesis and characterization of cellulose nanocrystals as reinforcing agent in solely palm based polyurethane foam. In: AIP conference proceedings, 2017. vol 1. AIP Publishing LLC, p 020042

Shi W, Ching YC, Chuah CH (2021) Preparation of aerogel beads and microspheres based on chitosan and cellulose for drug delivery: a review. Int J Biol Macromol 170:751-767 
Sinjari B, Pizzicannella J, D’Aurora M, Zappacosta R, Gatta V, Fontana A, Trubiani O, Diomede F (2019) Curcumin/liposome nanotechnology as delivery platform for anti-inflammatory activities via NFkB/ERK/pERK pathway in human dental pulp treated with 2-hydroxyethyl methacrylate (HEMA). Front Physiol 10:633

Sun X, Liu Y, Li C, Wang X, Zhu R, Liu C, Liu H, Wang L, Ma R, Fu M (2017) Recent advances of curcumin in the prevention and treatment of renal fibrosis. Biomed Res Int 2017:2418671. https://doi.org/10.1155/2017/2418671

Sung JC, Pulliam BL, Edwards DA (2007) Nanoparticles for drug delivery to the lungs. Trends Biotechnol 25:563-570

Suravajhala R, Parashar A, Malik B, Nagaraj VA, Padmanaban G, Kavi Kishor P, Polavarapu R, Suravajhala P (2020) Comparative docking studies on curcumin with COVID-19 proteins. Preprints

Thennakoon MSUG, Ching YC, Hiroshi U, Chuah CH (2021) Nanotherapeutics for treating coronavirus diseases. J Drug Deliv Sci Technol 64:102634

Ting D, Dong N, Fang L, Lu J, Bi J, Xiao S, Han H (2018) Multisite inhibitors for enteric coronavirus: antiviral cationic carbon dots based on curcumin. ACS Appl Nano Mater 1:5451-5459

Titto M, Ankit T, Saumya B, Gausal A, Sarada S (2020) Curcumin prophylaxis refurbishes alveolar epithelial barrier integrity and alveolar fluid clearance under hypoxia. Respir Physiol Neurobiol 274:103336

Tourkina E, Gooz P, Oates JC, Ludwicka-Bradley A, Silver RM, Hoffman S (2004) Curcumin-induced apoptosis in scleroderma lung fibroblasts: role of protein kinase. C $\varepsilon$ Am J Respir Cell Mol Biol 31:28-35

Udeni Gunathilake TMS, Ching YC, Chuah CH (2017a) Enhancement of curcumin bioavailability using nanocellulose reinforced chitosan hydrogel. Polymers 9:64

Udeni Gunathilake TMS, Ching YC, Chuah CH, Luqman CA (2017b) Biomedical and microbiological applications of bio-based porous materials: a review. Polymers 9:160

Udeni Gunathilake TMS, Ching YC, Chuah CH, Sabariah J, Lin PC (2016) Fabrication of porous materials from natural/ synthetic biopolymers and their composites. Materials 9:991

Umemoto Y, Uchida S, Yoshida T, Shimada K, Kojima H, Takagi A, Tanaka S, Kashiwagura Y, Namiki N (2020) An effective polyvinyl alcohol for the solubilization of poorly water-soluble drugs in solid dispersion formulations. J Drug Deliv Sci Technol 55:101401

Ummartyotin S, Manuspiya H (2015) A critical review on cellulose: from fundamental to an approach on sensor technology. Renew Sustain Energy Rev 41:402-412

Vartak R, Patil SM, Saraswat A, Patki M, Kunda NK, Patel K (2021) Aerosolized nanoliposomal carrier of remdesivir: an effective alternative for COVID-19 treatment in vitro. Nanomedicine 16:1187-1202

Vedula VB, Chopra M, Joseph E, Mazumder S (2016) Preparation and characterization of nanoparticles of carboxymethyl cellulose acetate butyrate containing acyclovir. Appl Nanosci 6:197-208

Venkatesan N, Chandrakasan G (1995) Modulation of cyclophosphamide-induced early lung injury by curcumin, an anti-inflammatory antioxidant. Mol Cell Biochem 142:79-87
Venkatesan N (1999) Pulmonary protective effects of curcumin against paraquat toxicity. Life Sci 66:PL21-PL28

von Rhein C, Weidner T, Henß L, Martin J, Weber C, Sliva K, Schnierle BS (2016) Curcumin and Boswellia serrata gum resin extract inhibit chikungunya and vesicular stomatitis virus infections in vitro. Antiviral Res 125:51-57

Wen C-C, Kuo Y-H, Jan J-T, Liang P-H, Wang S-Y, Liu H-G, Lee C-K, Chang S-T, Kuo C-J, Lee S-S (2007) Specific plant terpenoids and lignoids possess potent antiviral activities against severe acute respiratory syndrome coronavirus. J Med Chem 50:4087-4095

Wulandari W, Rochliadi A, Arcana I (2016) Nanocellulose prepared by acid hydrolysis of isolated cellulose from sugarcane bagasse. In: IOP conference series: materials science and engineering. vol 1. IOP Publishing, p 012045

Xu M, Deng B, Chow Y-1, Zhao Z-z, Hu B (2007) Effects of curcumin in treatment of experimental pulmonary fibrosis: a comparison with hydrocortisone. J Ethnopharmacol 112:292-299

Xu X, Cai Y, Yu Y (2018) Effects of a novel curcumin derivative on the functions of kidney in streptozotocininduced type 2 diabetic rats. Inflammopharmacology 26:1257-1264

Yang J, Ching YC, Chuah CH (2019) Applications of lignocellulosic fibers and lignin in bioplastics: a review. Polymers 11:751-777

Zachar O (2020) Formulations for COVID-19 Early stage treatment via silver nanoparticles inhalation delivery at home and hospital. ScienceOpen Preprints

Zahedipour F, Hosseini SA, Sathyapalan T, Majeed M, Jamialahmadi T, Al-Rasadi K, Banach M, Sahebkar A (2020) Potential effects of curcumin in the treatment of COVID19 infection. Phytother Res 34:2911-2920

Zhang H, Zhu W, Jin Q, Pan F, Zhu J, Liu Y, Chen L, Shen J, Yang Y, Chen Q (2021) Inhalable nanocatchers for SARSCoV-2 inhibition. Proc Natl Acad Sci 118(29):e2102957118. https://doi.org/10.1073/pnas. 2102957118

Zhang L, Man S, Qiu H, Liu Z, Zhang M, Ma L, Gao W (2016) Curcumin-cyclodextrin complexes enhanced the anti-cancer effects of curcumin. Environ Toxicol Pharmacol 48:31-38

Zheng D, Zhang Y, Guo Y, Yue J (2019) Isolation and characterization of nanocellulose with a novel shape from walnut (Juglans regia L.) shell agricultural waste. Polymers 11:1130

Zoppe JO, Ruottinen V, Ruotsalainen J, Rönkkö S, Johansson L-S, Hinkkanen A, Järvinen K, Seppälä J (2014) Synthesis of cellulose nanocrystals carrying tyrosine sulfate mimetic ligands and inhibition of alphavirus infection. Biomacromol 15:1534-1542

Zsila F, Bikádi Z, Simonyi M (2004) Circular dichroism spectroscopic studies reveal $\mathrm{pH}$ dependent binding of curcumin in the minor groove of natural and synthetic nucleic acids. Org Biomol Chem 2:2902-2910

Publisher's Note Springer Nature remains neutral with regard to jurisdictional claims in published maps and institutional affiliations. 